IVr

المشكلات الأسرية وعلاقتها بأداء الزوجة لأدوارها الزوجية دراسة ببعض قري محافظة الغربية

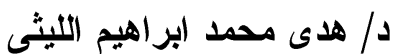 \\ مدرس بقسم تتمية الأسرة الريفية - كلية الإقتصاد المنزلىـــامعة الازهر
}

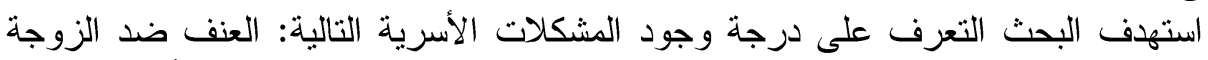

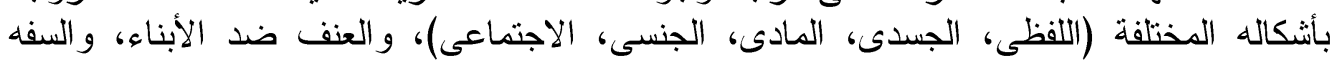

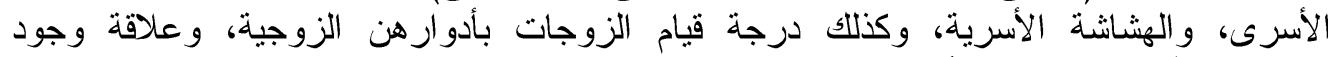
المشكلات بأداء المبحوثات لأدو ارهن الأند المدروسة.

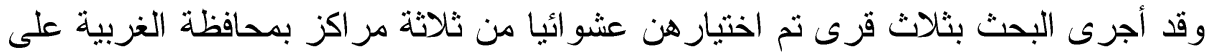

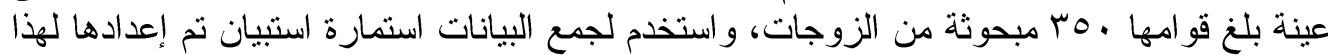

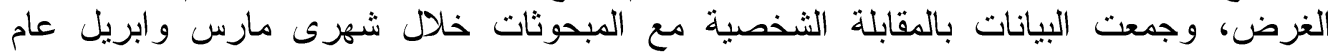

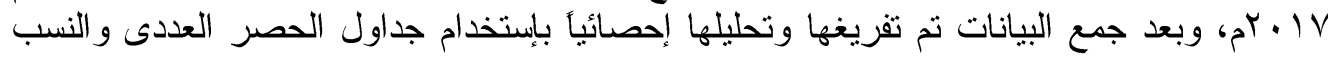
المئوية ومعامل الارنباط البسيط لبيرسون.

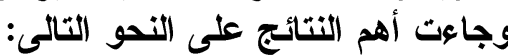

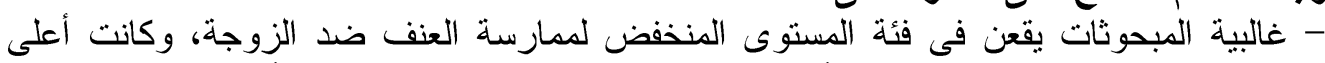

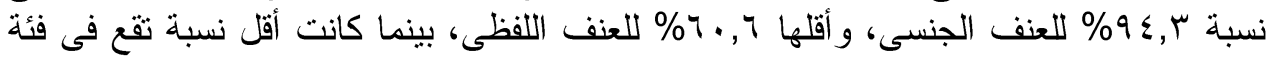

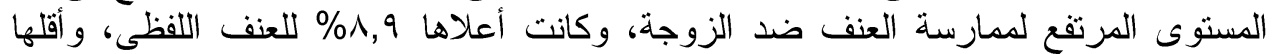

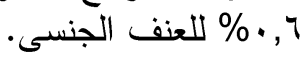

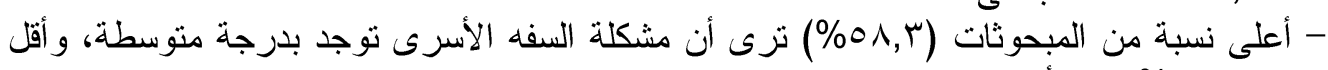

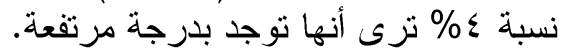

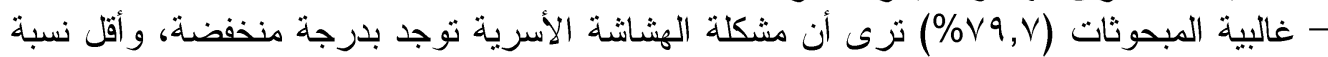

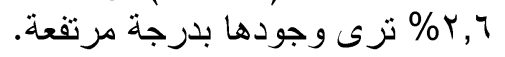

- غالبية المبحوثات تزى أنها تقوم بادو ارها ها الزوجية بدرجة مرتفعة وهى وهى: التغذية، ورعاية الاطفال

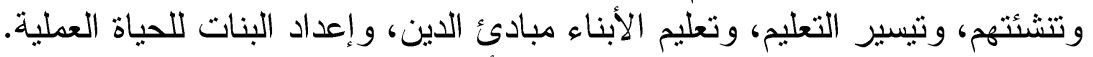

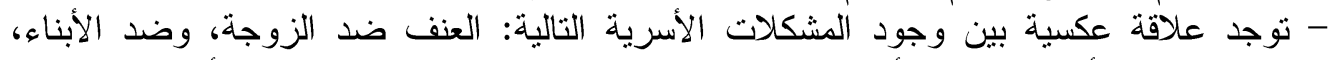

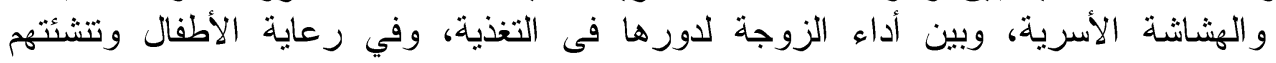
و و إعدادهم للحياة العملية. - توجد علاقة طردية بين وجود المشكلات الأسرية التالية: العنف ضد الزية الزوجة، و السفه الأسرى، وبين أداء الزوجة لدودة لدورها كقدوة للأبناء.

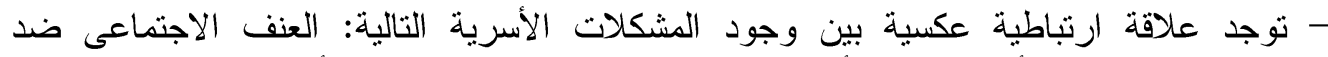

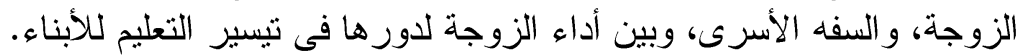

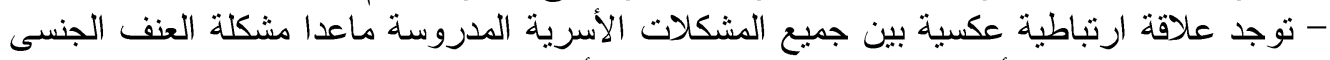

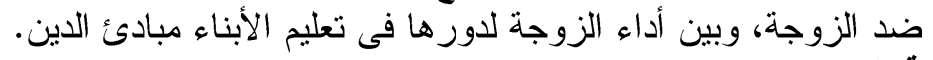

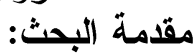

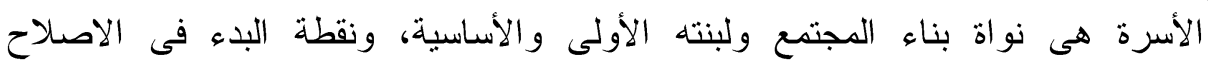

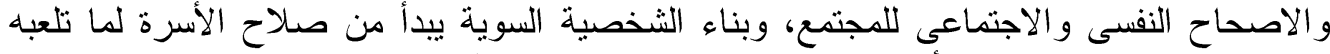

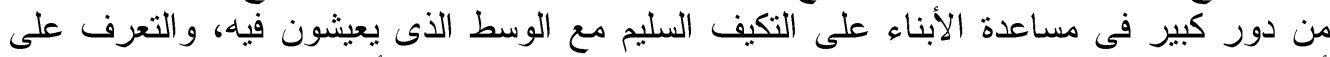

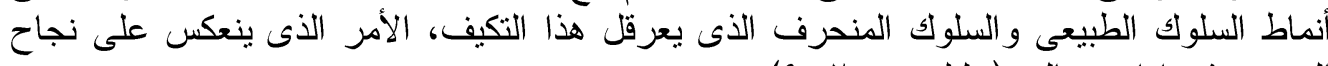
المجتمع فى اداء رسالته (خليل: . . . r. 9. 9).

Fayoum J. Agric. Res. \& Dev., Vol. 32, No.1, January, 2018 
IV $\varepsilon$

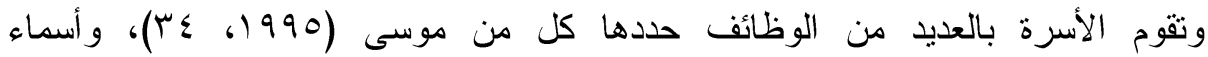

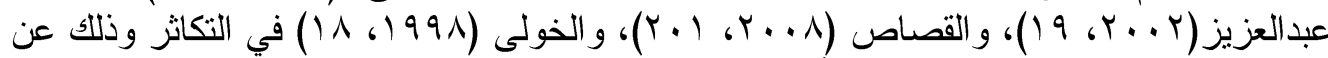

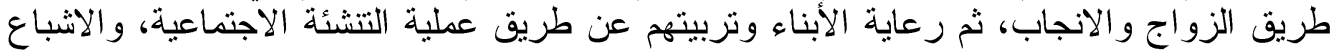

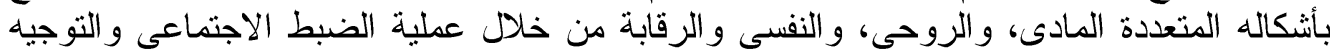

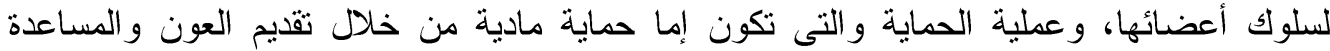

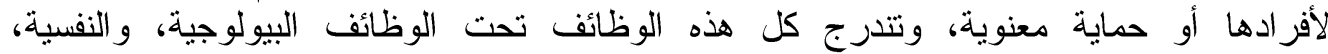

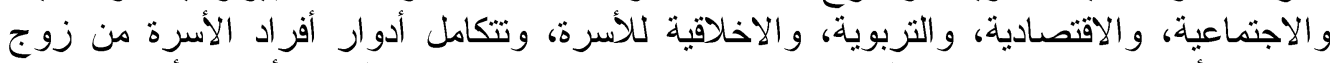

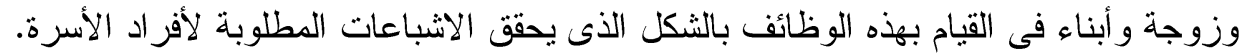

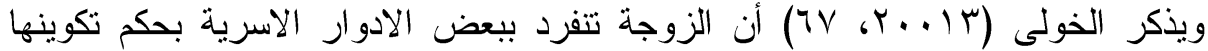

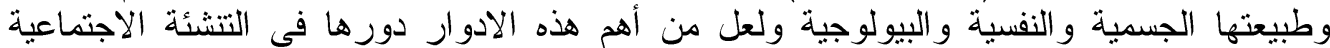

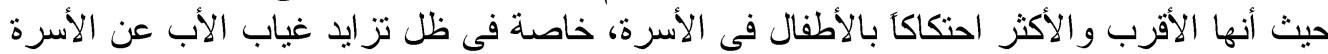

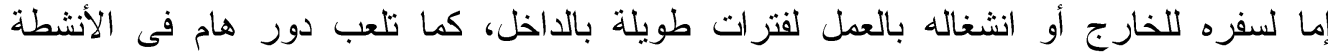

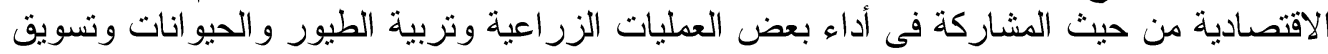

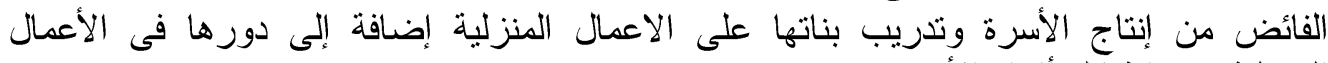
المنزلية ورعاية كل أفراد الأسرة.

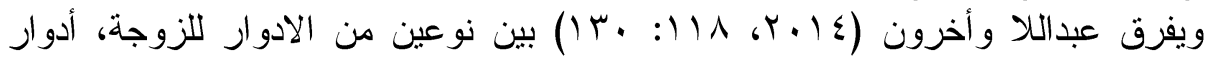

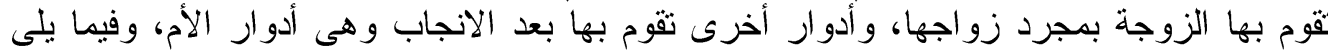

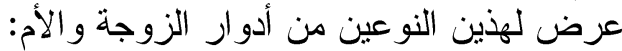

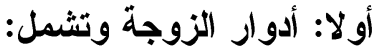

اـ إدارة المنزل: حيث تقوم الزوجة الزولة بتصريف موارد الأسرة بما يحقق مصالحها وذللك بتوزيعها

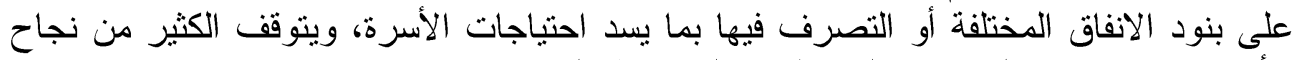

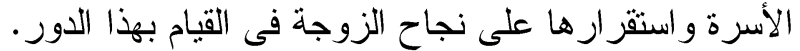

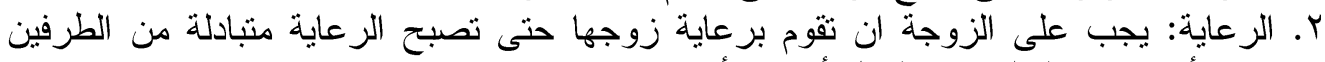

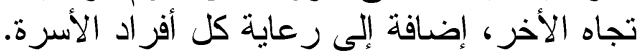

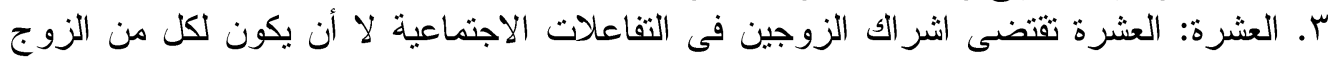

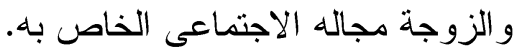

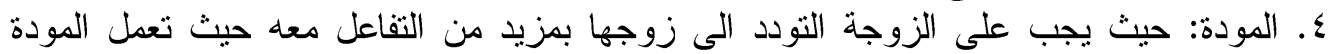

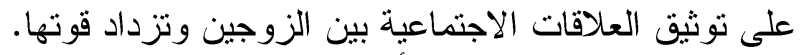

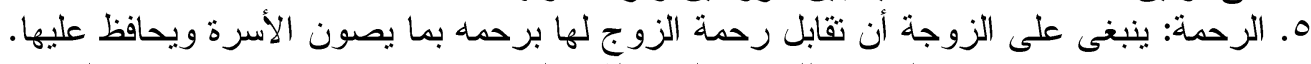

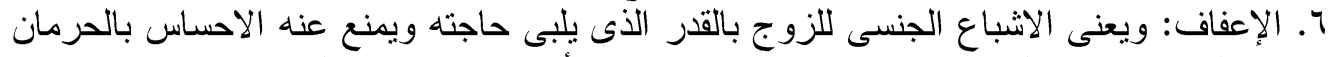

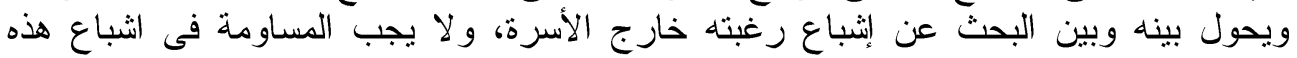

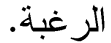
V. الو لاء: ويقصد به الارتباط بالاسرة وتقديم صالح الأسرة على أى اعتبارات أخرى، وتتبع أهمية

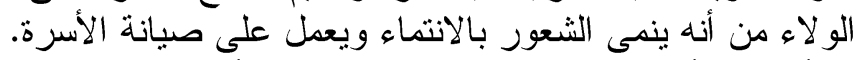

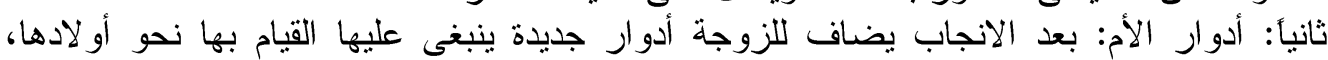
ويتضمن دور الأم ما يلى الإنى:

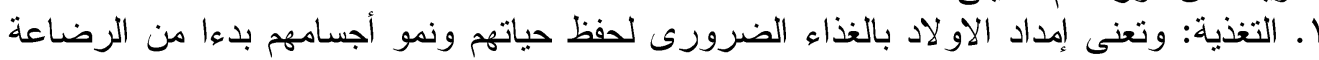

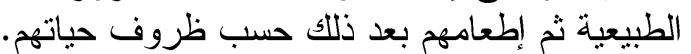

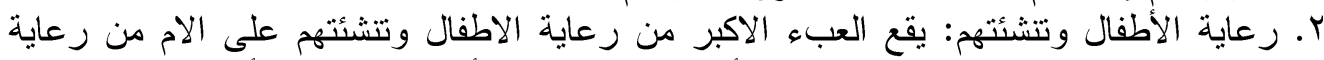

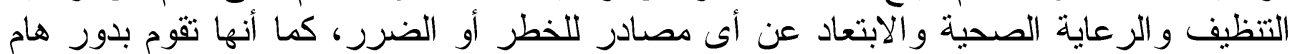

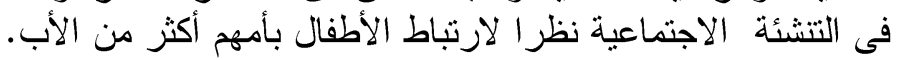

Fayoum J. Agric. Res. \& Dev., Vol. 32, No.1, January, 2018 
ivo

r. القدوة: حيث تلتزم الام أمام أطفالها بالأقوال والأفعال المقبولة اجتماعيا وتتمنى أن يتعلمها أطفالها.

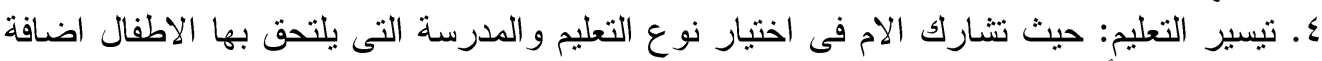

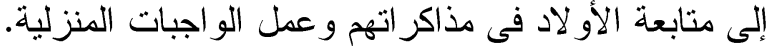

0. الاعداد للحياة العملية: حيث يقع على الأم العبء الأكبر فى إعداد الإناث بصفة خاصة للحياة

العملية.

7. تعليم مبادئ الدين: يقع على الام بجانب دور الأب تعليم الطفل مبادئ دينه منذ الطفولة حتى ينشأ

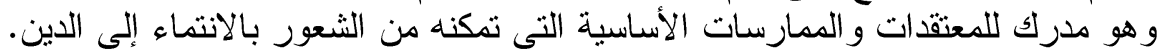

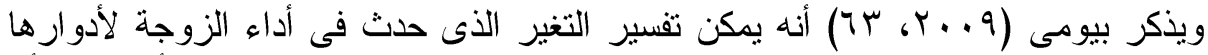

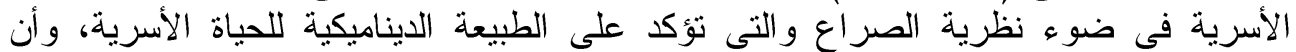

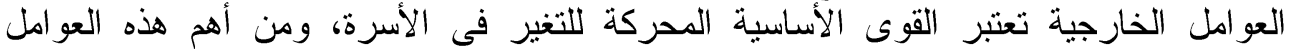

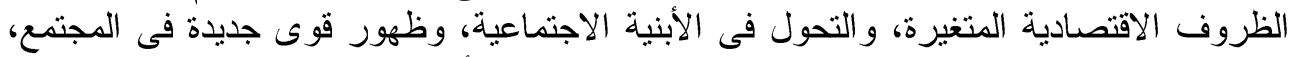

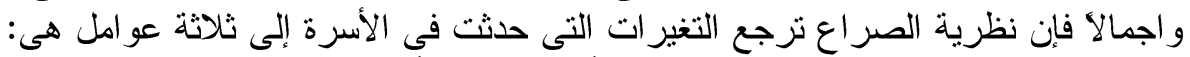

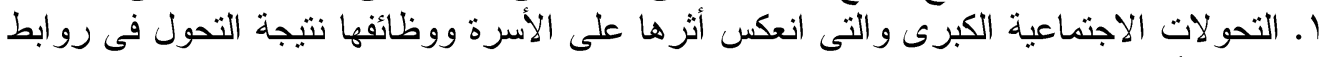

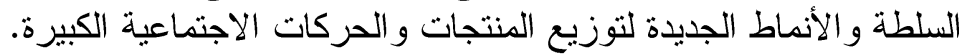
r. التحضر الاجبارى و الهجرة من الريف إلى الحضر و الذى أدى إلى حدوث تغيرات كبيرة فى بناء

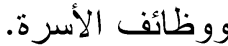
ب. الزيادة الكبيرة فى النشاط الاقتصادى، وخروج المر أة إلى العمل للمساعدة فى تكاليف معيشة

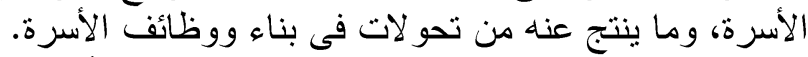

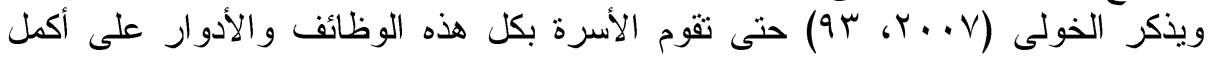

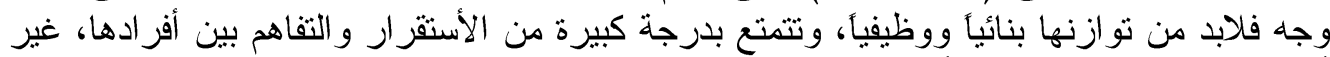

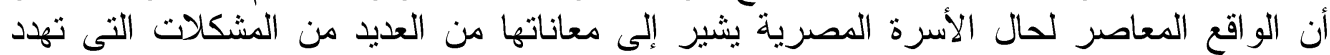

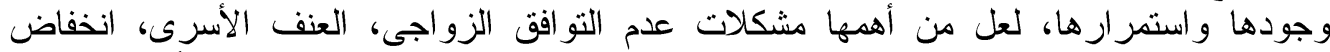

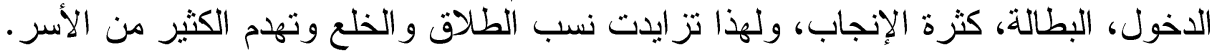

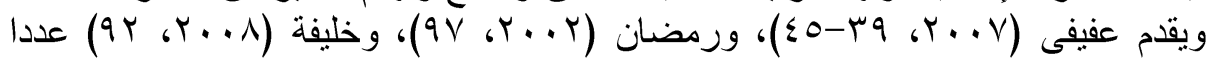

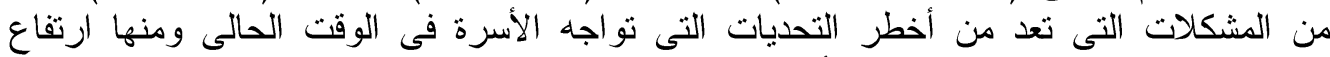

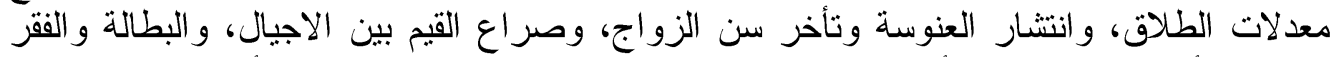

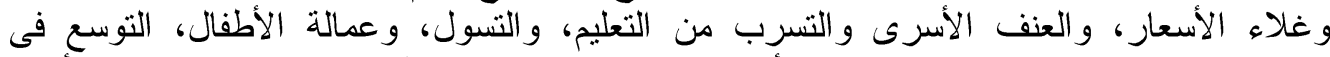

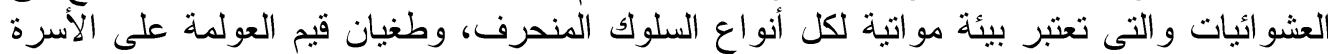

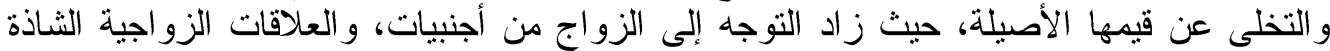

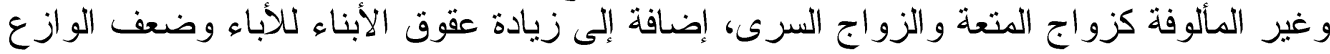

ولا شك أن كل هذه المشكلات يكون لها تأثير سلبى على أداء الأسرة لوظائفها و أدوارها

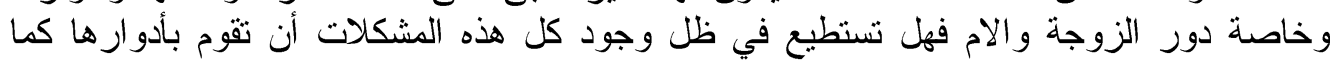

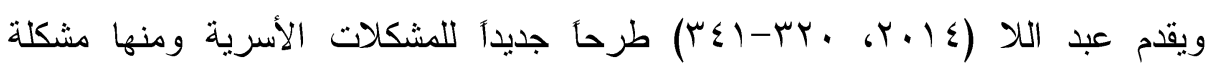
ينبغى.

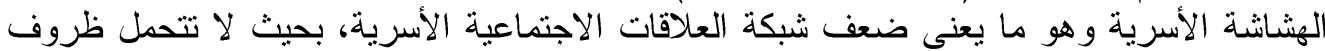

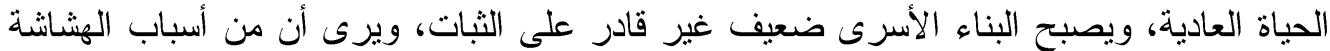

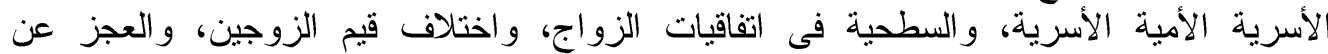

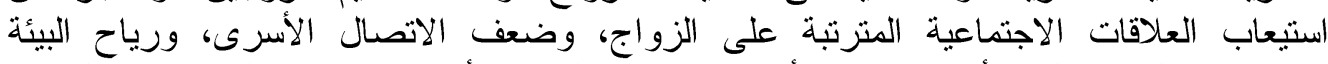

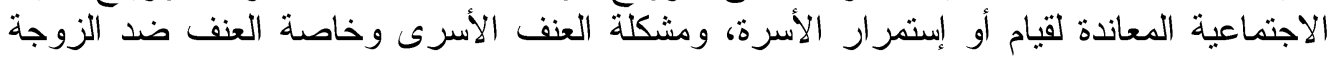

Fayoum J. Agric. Res. \& Dev., Vol. 32, No.1, January, 2018 
$1 \vee 7$

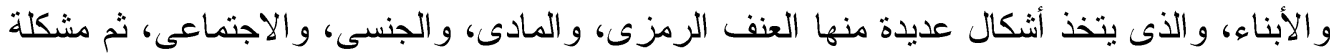

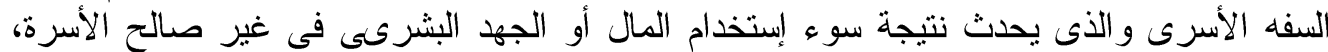

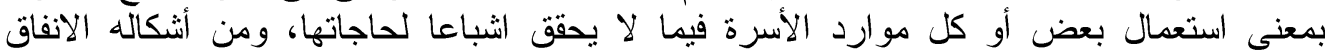

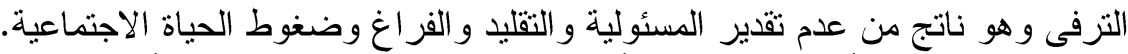

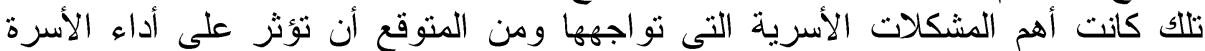

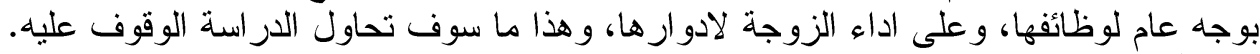

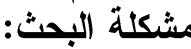

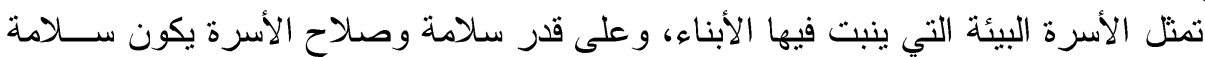

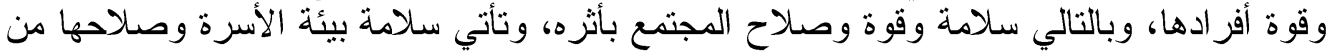

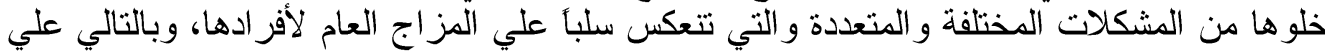

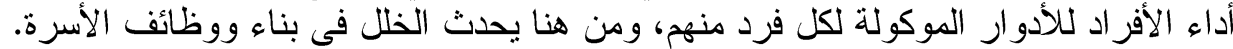

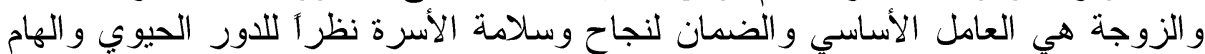

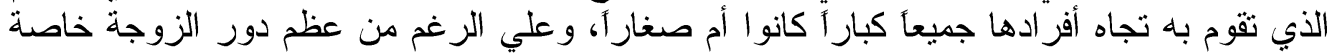

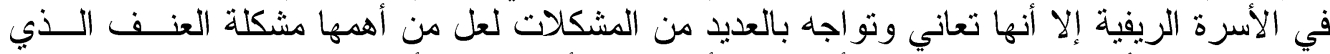

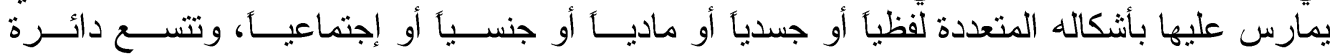

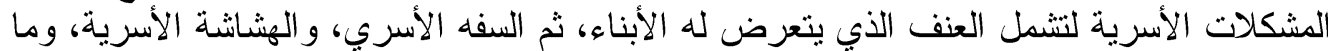

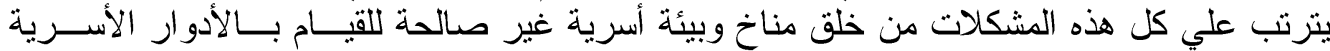

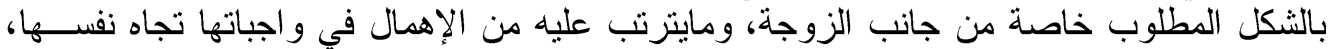

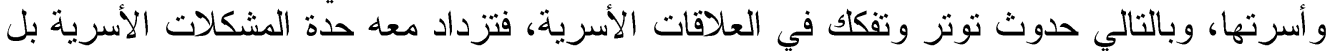

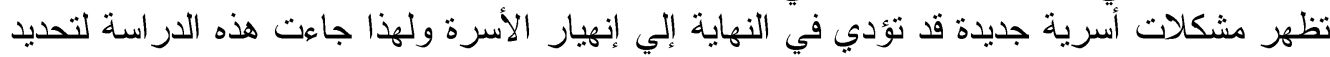

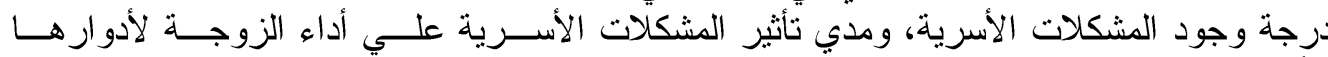

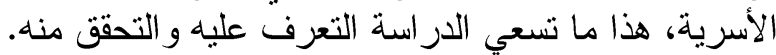

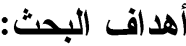

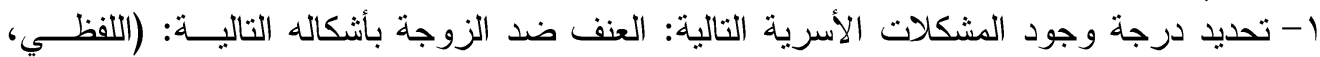

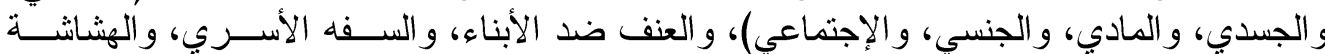

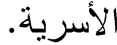

r- تحديد درجة أداء الزوجات المبحوثات لأدوارهن الأسرية التالية: تغذية الأسرة، رعاية الأطفال

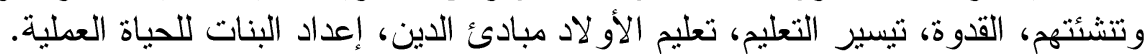

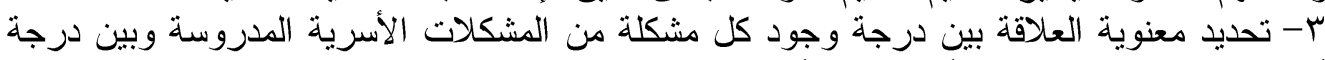

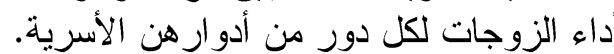

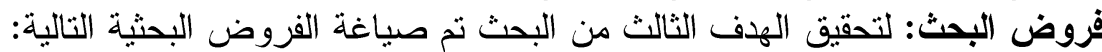

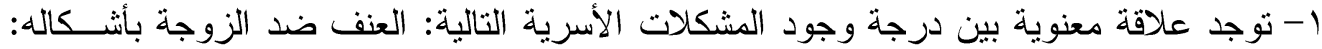

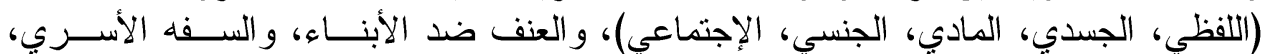

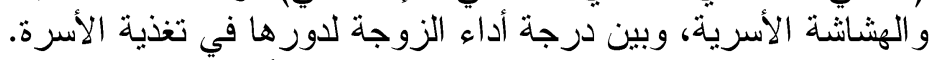

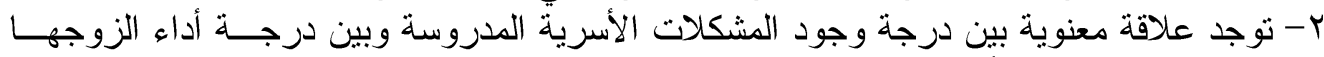
لدور ها في رعاية الأطفال وتنشئتهر.

ب- توجد علاقة معنوية بين درجة وجود المشكلات الأسرية المدروسة وبين درجــة أداء الزورجـة لأدور ها كقدوة في الأسرة.

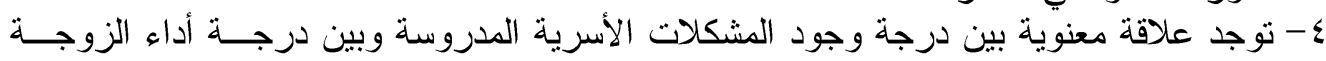
لدور ها في تيسير التعليم للأبناء.

Fayoum J. Agric. Res. \& Dev., Vol. 32, No.1, January, 2018 
IVV

ه- توجد علاقة معنوية بين درجة وجود المشكلات الأسرية المدروسة وبين درجــة أداء الزوجـــة

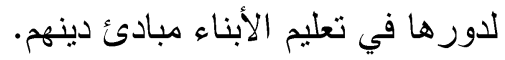

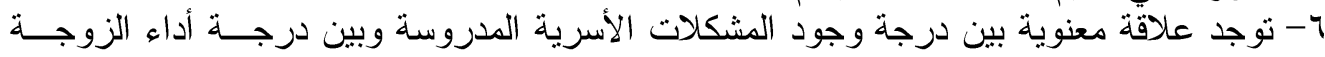
لدور ها في إعداد البنات للحياة العملية.

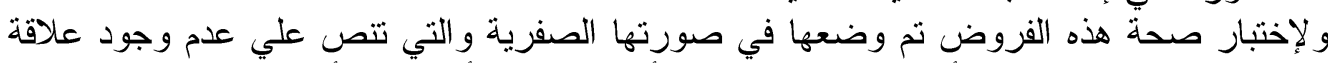

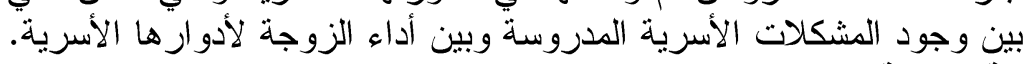

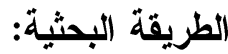

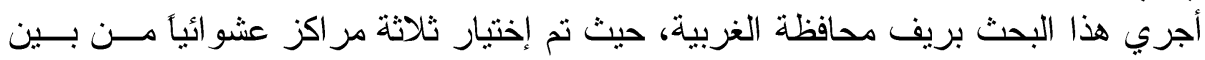

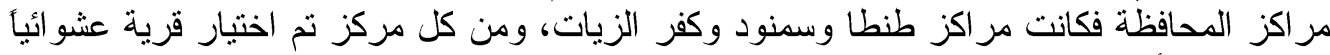

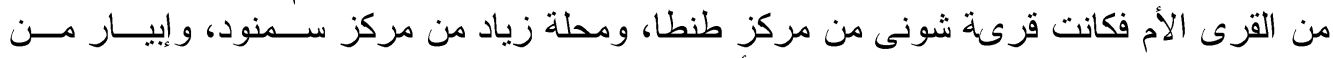

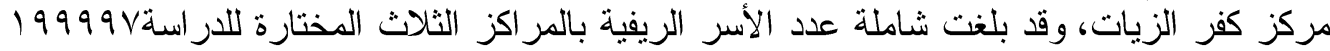

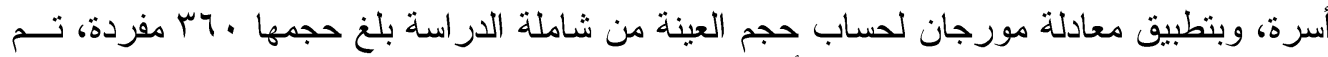

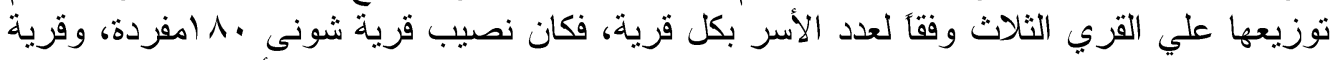

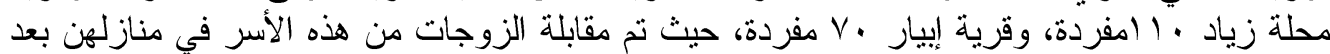

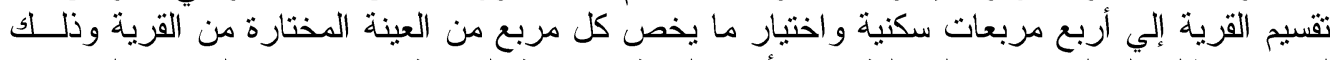

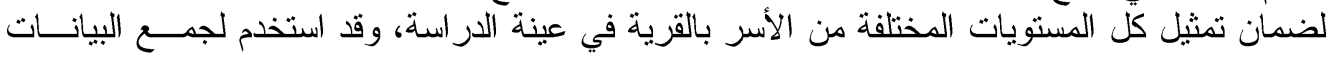

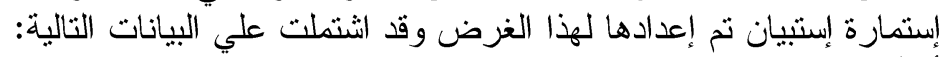

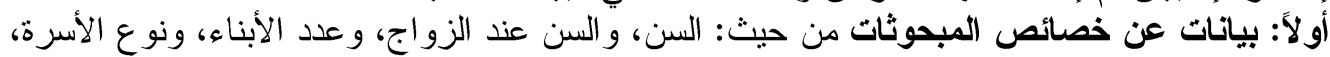

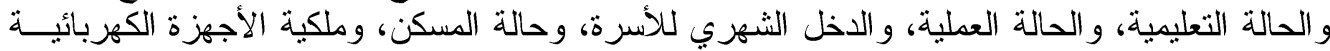

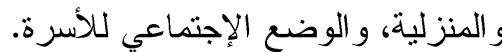
أنانياً: بيانات عن وجود المشكلات الأسرية وهي:-

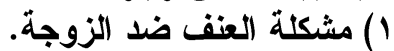

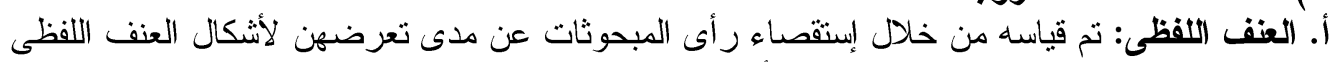

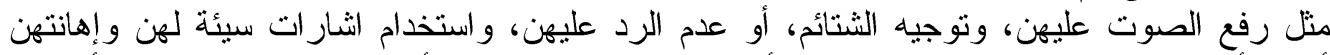

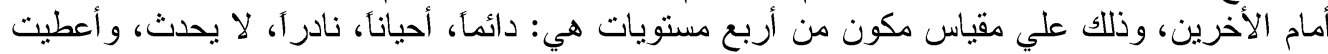

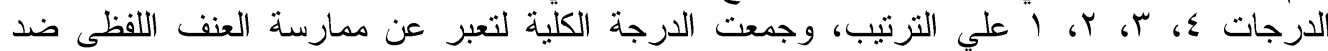

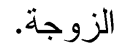

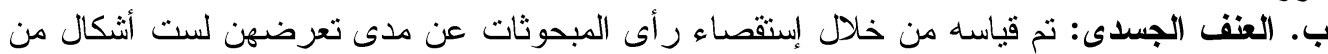

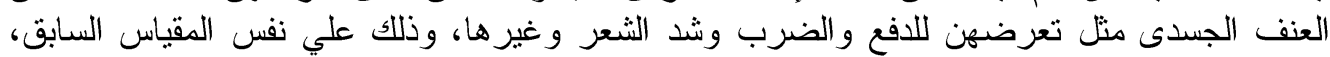

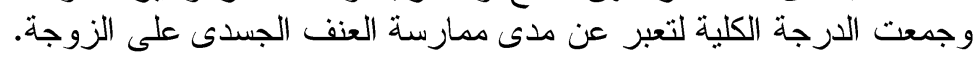

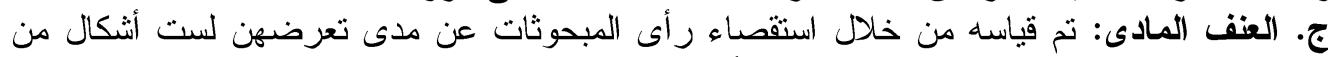

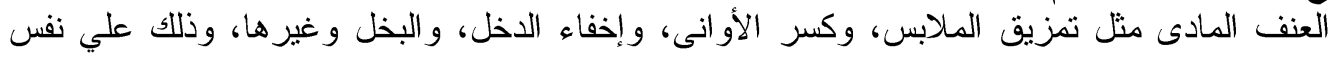

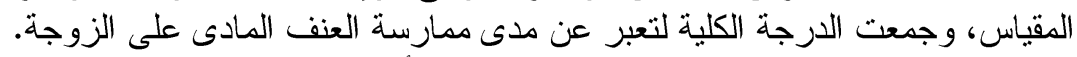

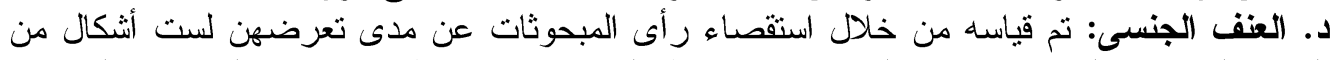

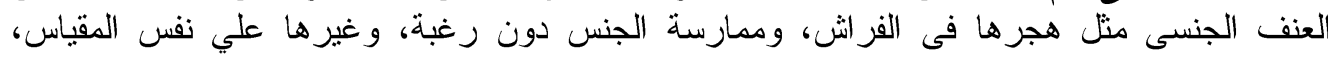

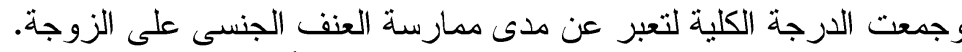

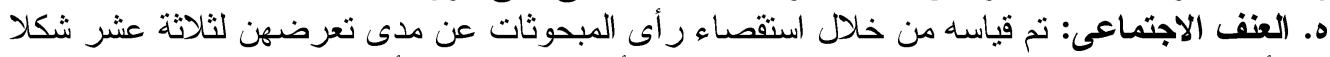

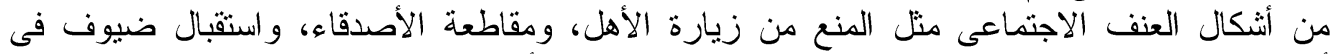

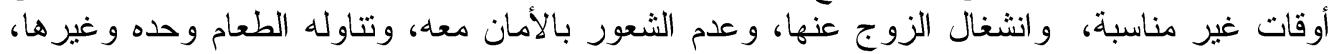

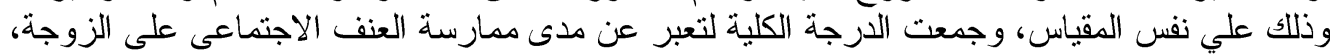

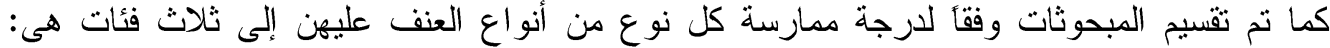
يمارس بدرجة منخفضة، متوسطة، ومرتفعة.

Fayoum J. Agric. Res. \& Dev., Vol. 32, No.1, January, 2018 
IVA

1) مشكلة العنف ضد الأبناء: نم قياسها بإستقصاء رأى المبحوثات عن مدى تعرض الأبناء في الأســرة

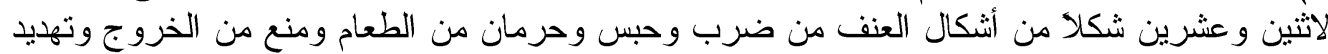

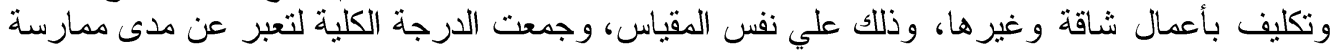

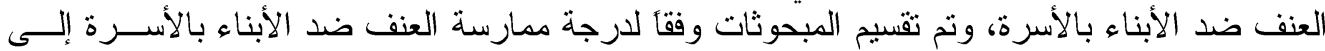

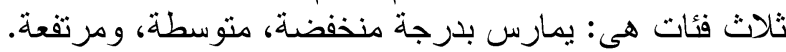

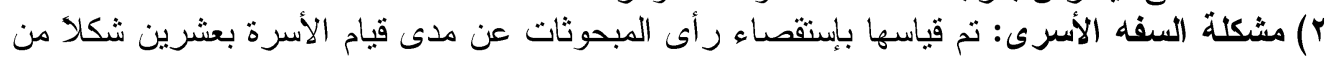

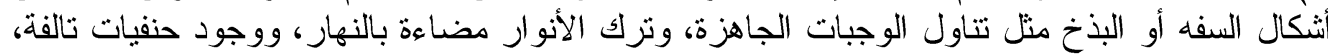

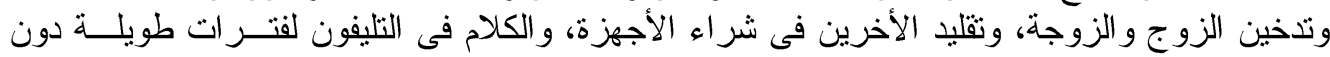

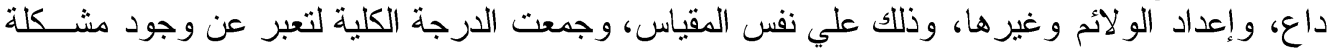

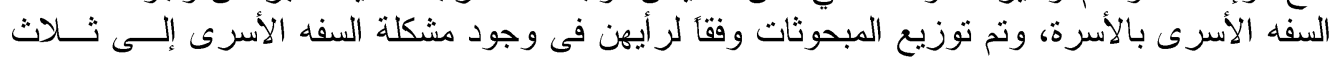

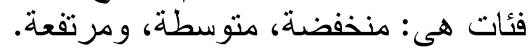

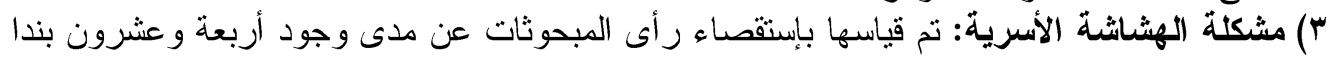

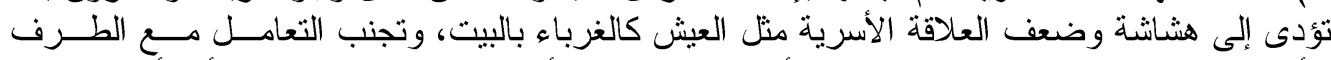

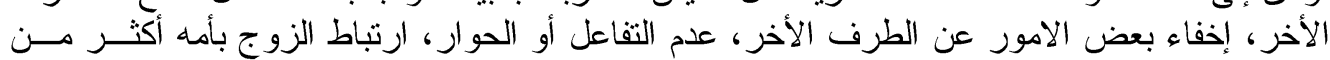

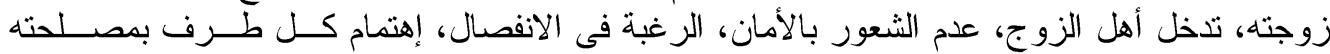

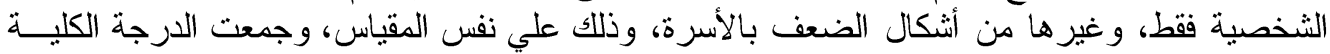

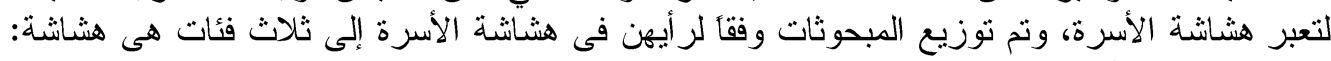

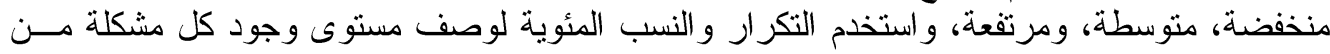

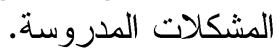

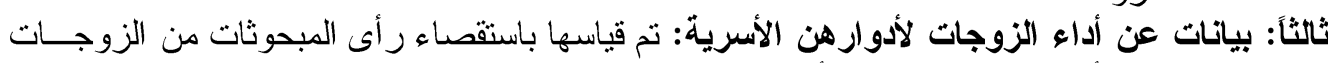

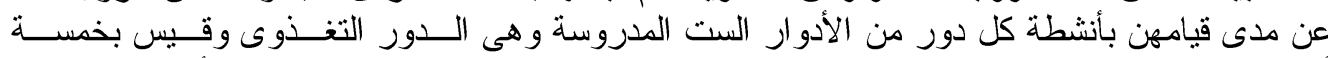

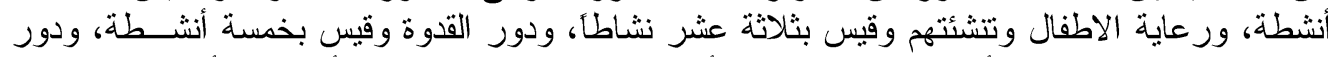

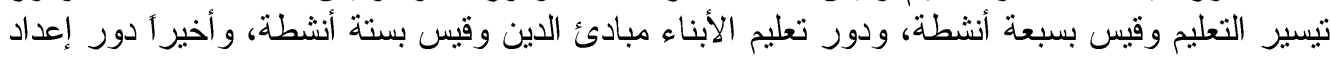

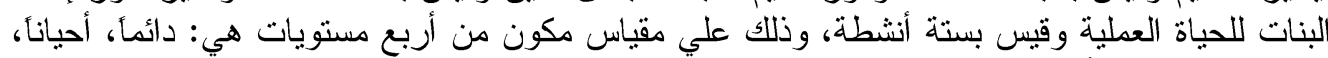

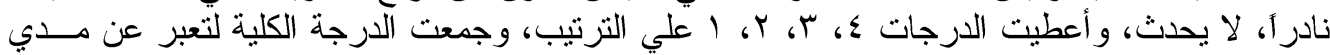

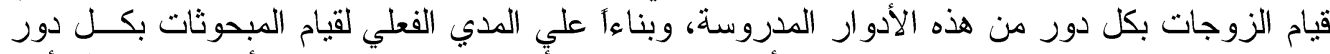

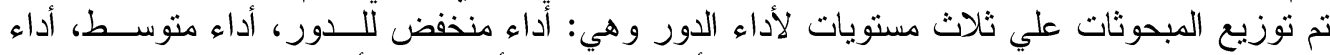

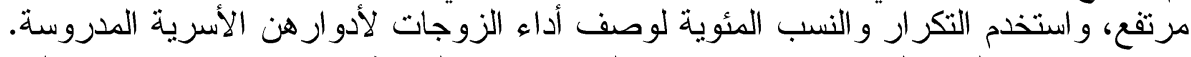

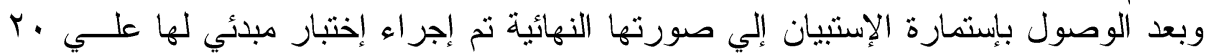

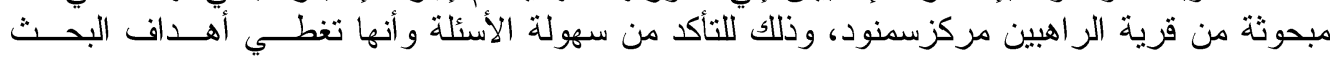

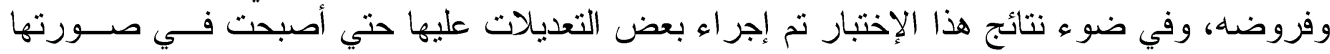

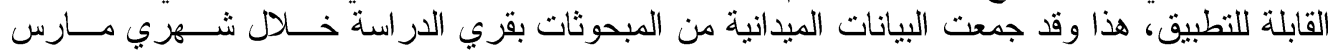

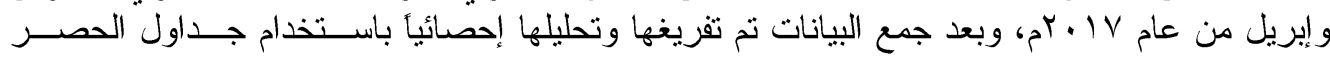
العددي و النسب المئوية ومعامل الإرتباط البسيط. نتائج البحث: البث:

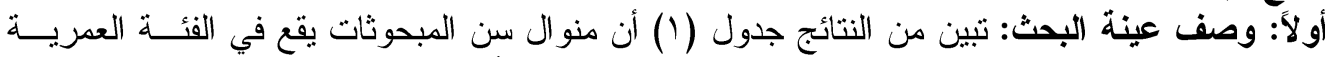

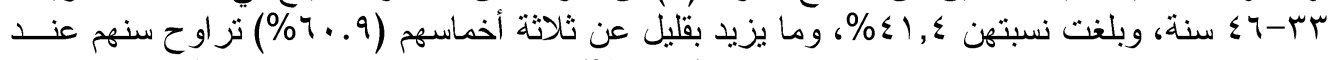

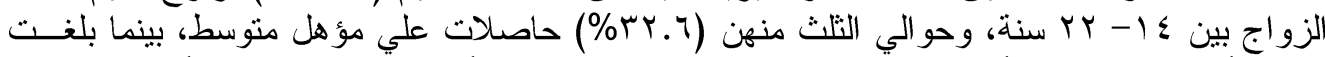

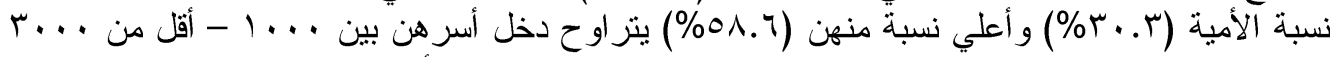

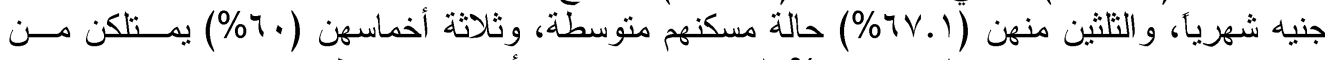

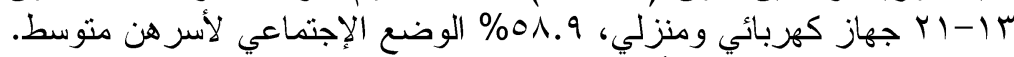

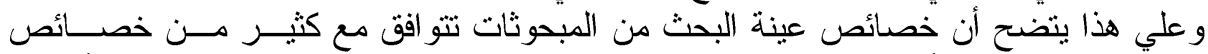

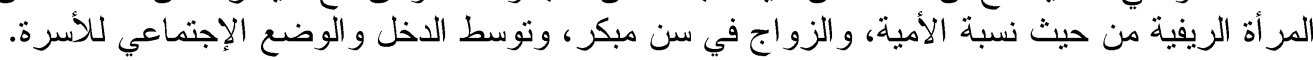

Fayoum J. Agric. Res. \& Dev., Vol. 32, No.1, January, 2018 
جدول (1) : توزيع المبحوثات من الزوجات وفقا لبعض خصائصهن المدروسة.

\begin{tabular}{|c|c|c|c|c|c|}
\hline$\%$ & عدد & الخصائص & $\%$ & عدد & الخصائص \\
\hline $\begin{array}{l}1 r, 4 \\
0 \wedge, 7 \\
r . \\
\Lambda, 9\end{array}$ & $\begin{array}{l}\varepsilon \varepsilon \\
r .0 \\
v . \\
r i\end{array}$ & 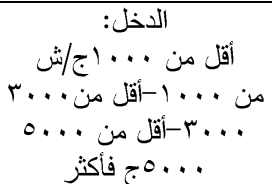 & $\begin{array}{l}r u \\
\varepsilon l, \varepsilon \\
r . \\
r, y\end{array}$ & $\begin{array}{l}91 \\
1 \leq 0 \\
1.0 \\
9\end{array}$ & 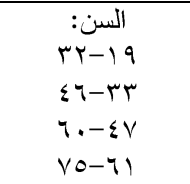 \\
\hline $\begin{array}{l}1 \%, V \\
T V, 1 \\
19,1\end{array}$ & $\begin{array}{l}\sum \Lambda \\
\text { Yro } \\
\text { TV }\end{array}$ & منخفضة/رديئة & $\begin{array}{l}7 ., q \\
r y, r \\
r, q\end{array}$ & $\begin{array}{l}r I T \\
1 r V \\
1 .\end{array}$ & 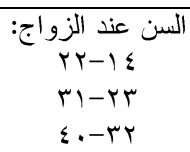 \\
\hline $\begin{array}{c}r, 1 \\
1 . \\
1,9\end{array}$ & $\begin{array}{l}1.9 \\
r i . \\
r i\end{array}$ & ملكية الأجهزة: & $\begin{array}{l}r \cdot, r \\
1 r, \varepsilon \\
r, \varepsilon \\
r, \varepsilon \\
r, r, 4 \\
17, q\end{array}$ & $\begin{array}{l}1.9 \\
\varepsilon V \\
1 r \\
11 \\
11 \varepsilon \\
09\end{array}$ & ثنالة الحزالة التعليمية: \\
\hline $\begin{array}{l}r 1, \varepsilon \\
0 \wedge, 9 \\
9, v\end{array}$ & $\begin{array}{l}11 . \\
r .4 \\
r \varepsilon\end{array}$ & منو منخف الطبقى: & & & الحالة المهنية \\
\hline
\end{tabular}

ثاتياً: مستوي وجود المشكلات الأسرية.

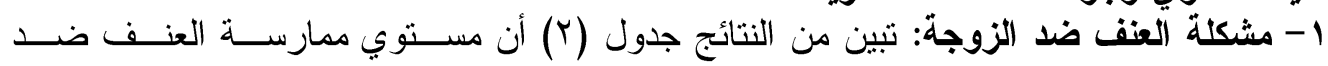

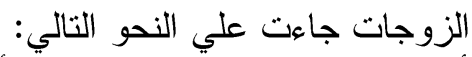

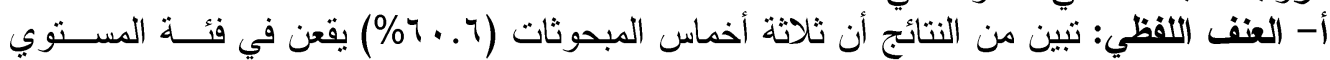

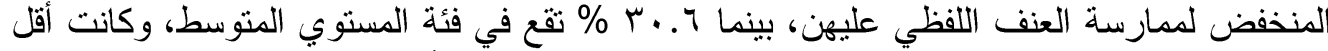

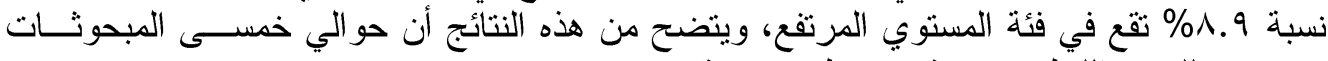

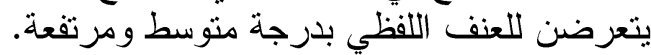

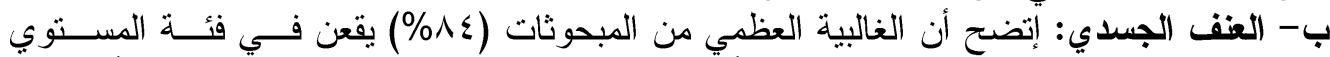

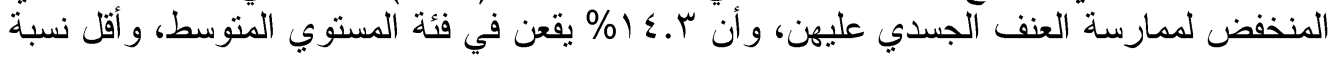

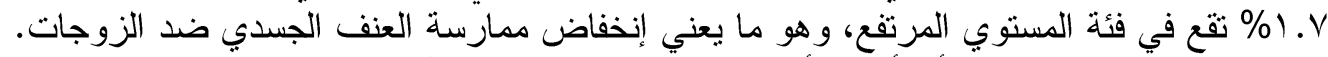

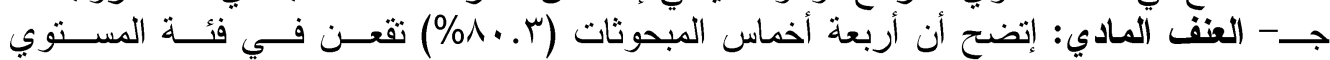

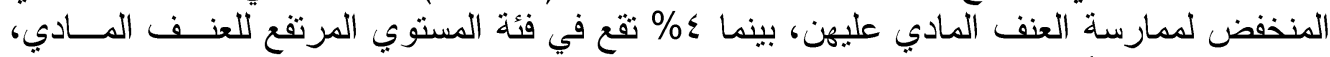

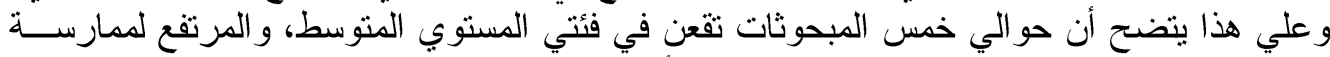

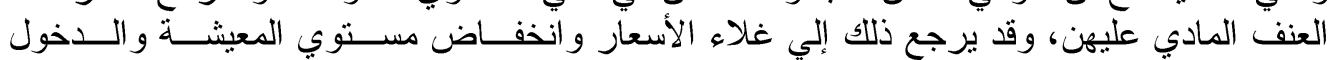
و الضغوط المادية علي رب الفي الأسرة.

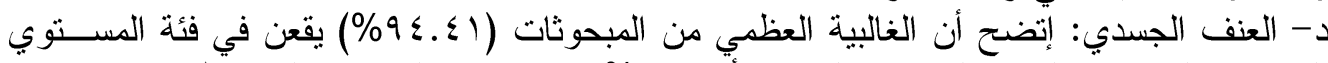

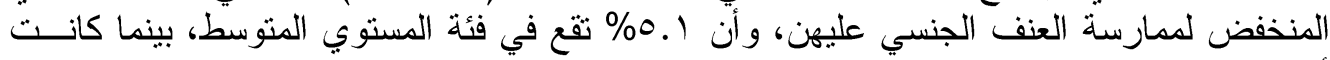

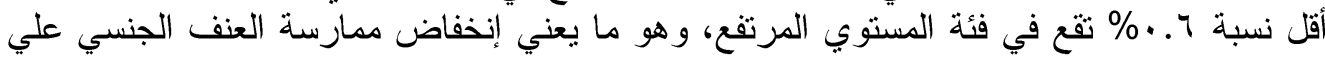

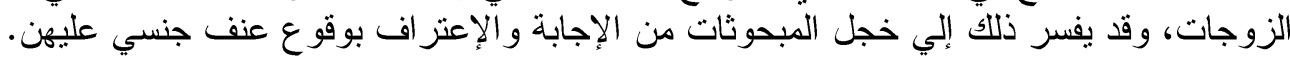

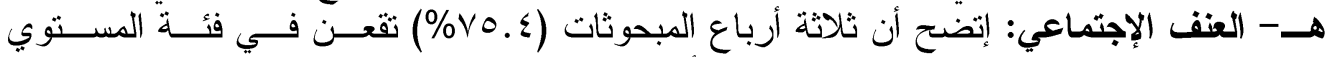

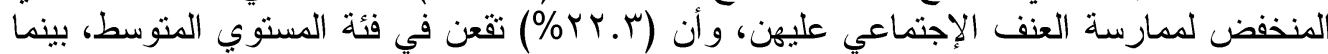

Fayoum J. Agric. Res. \& Dev., Vol. 32, No.1, January, 2018 
$1 \wedge$.

أقل نسبة r.ب\% تقعن في فئة المستوي المرتفع. و علي هذا يتضح أن حو الي ربع المبحوثات يقعن

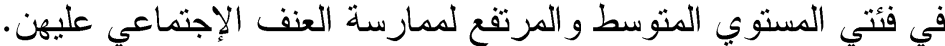

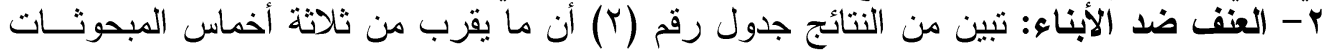

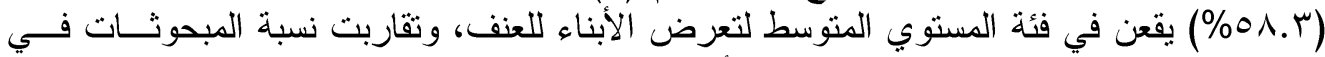

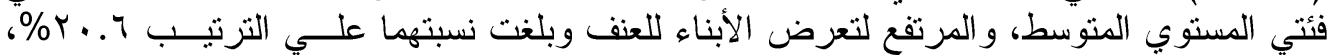

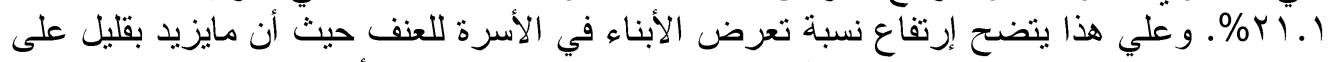

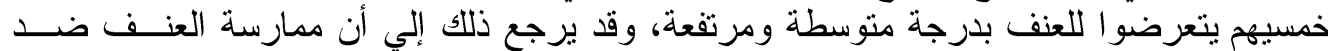
الأبناء يعتبر ضمن أنماط الثقافة الريفية لتربية الأبناء.

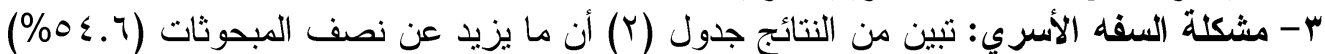

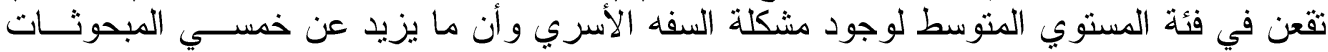

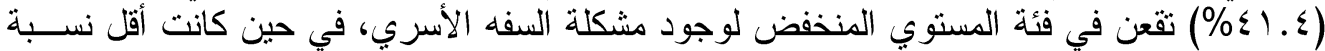

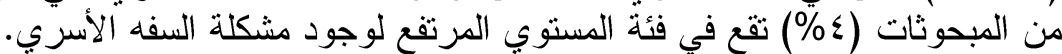

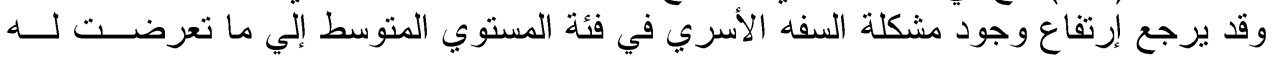

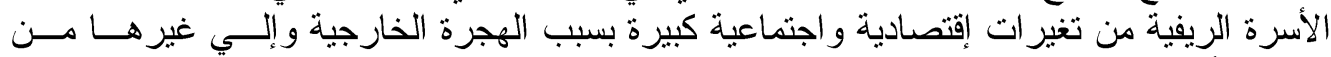
بعض الأنماط التقافية الدخيلة عليها خاصة فى مجال الإنفاق علي بنود وملذات غريبة التية عن طبيعـة

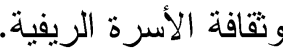

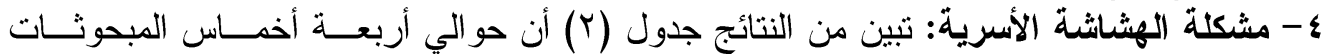

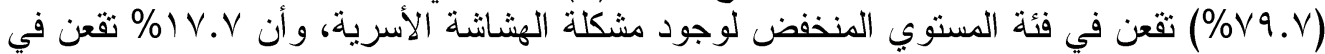

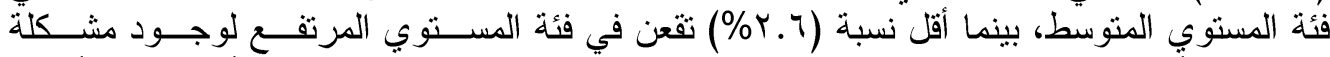

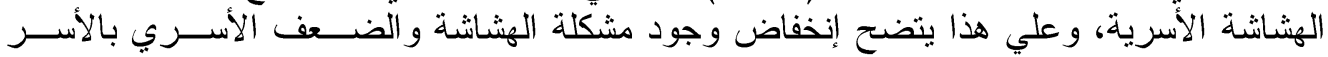

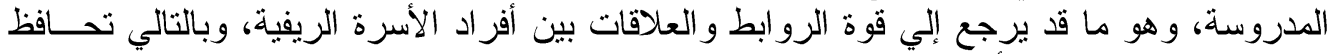
علي تماسكها وتتصدي لأي محاو لات النيل منها الزوا و إضعافها.

جدول ( r ): توزيع المبحوثات وفقا لمستوى وجود المشكلات الأسرية لديهن.

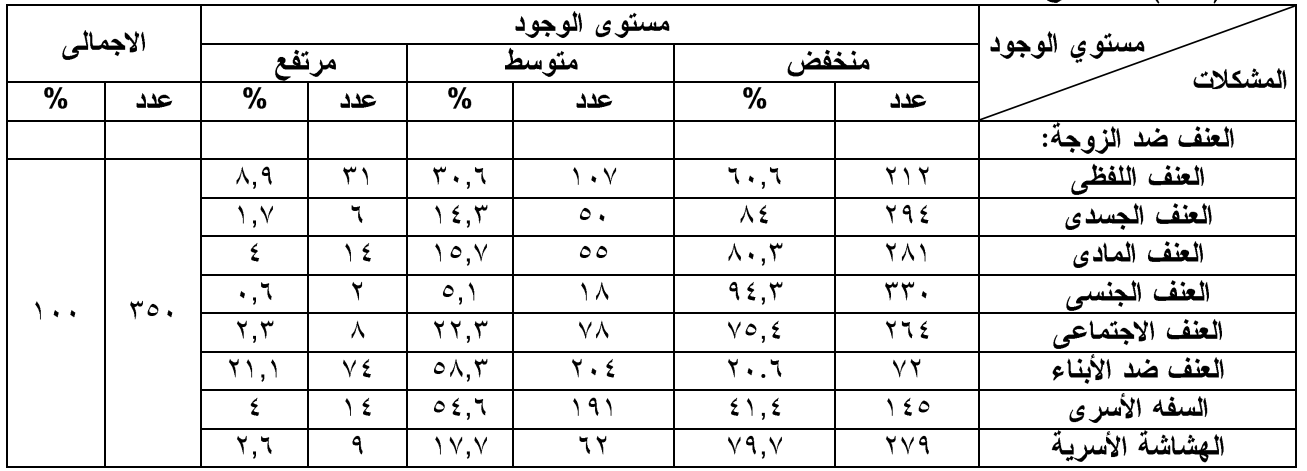

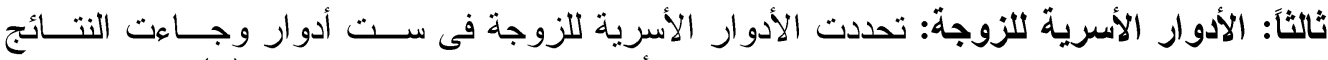

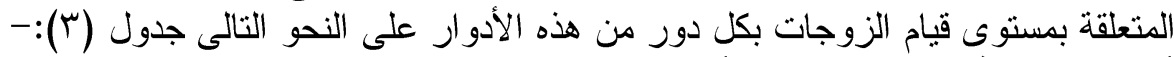

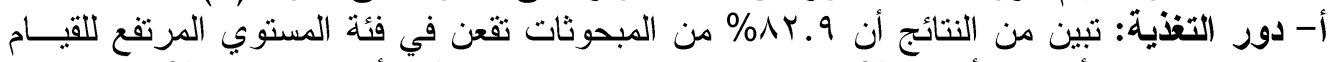

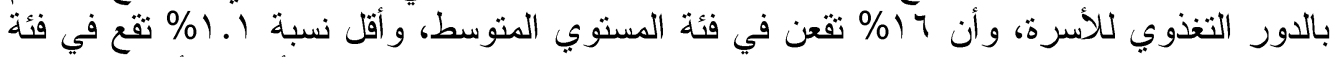

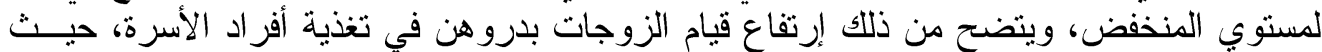

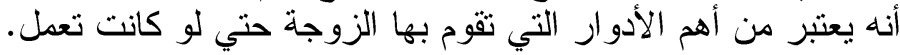

Fayoum J. Agric. Res. \& Dev., Vol. 32, No.1, January, 2018 
$|\wedge|$

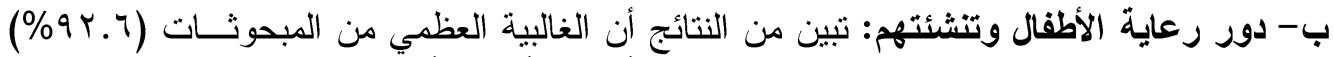

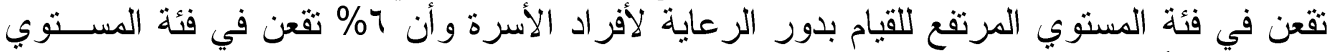

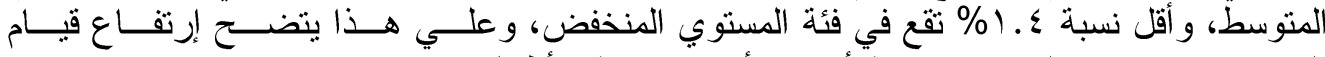
المبحوثات بدورهن الخاص برعاية أفر اد الأسرة وتنشئة الأطفال فيهاً.

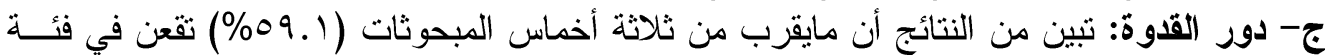

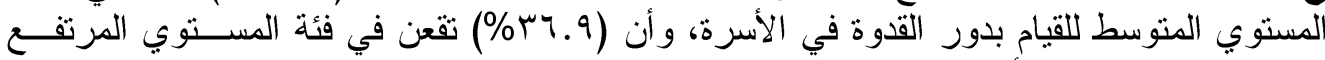

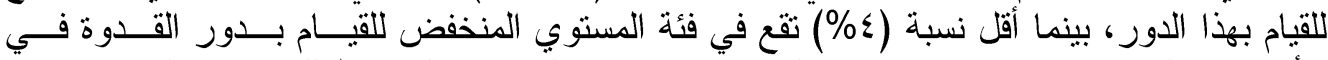

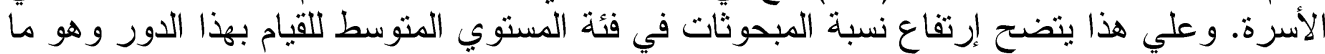

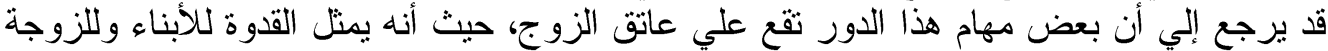

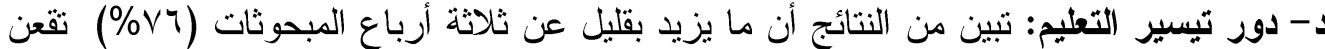

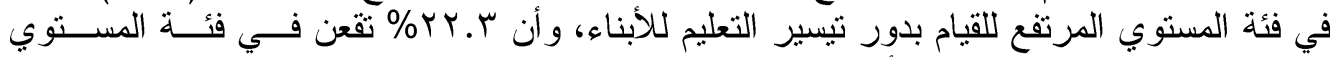

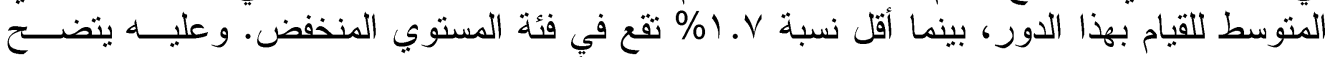

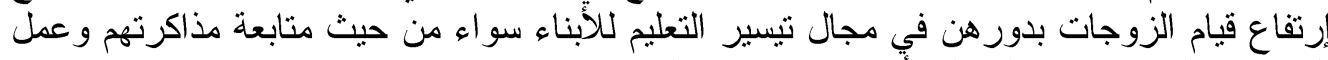

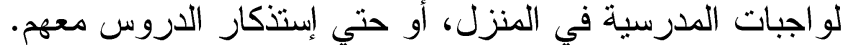

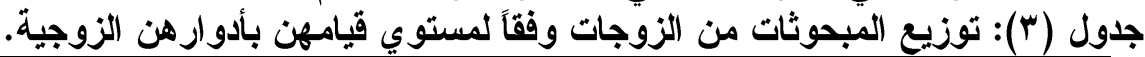

\begin{tabular}{|c|c|c|c|c|c|c|c|c|}
\hline \multicolumn{2}{|c|}{ الإجمالي } & \multicolumn{2}{|c|}{ مرتفع } & \multicolumn{2}{|c|}{ متوسط } & \multicolumn{2}{|c|}{ منخفض } & \multirow{2}{*}{ الأدوار } \\
\hline$\%$ & عدد & $\%$ & عدد & $\%$ & عدد & $\%$ & عدد & \\
\hline $1 \ldots$ & ro. & Ar.q & $r q$. & 17 & 07 & 1.1 & $\varepsilon$ & التغذية \\
\hline $1 \ldots$ & ro. & 94.7 & TrE & 7 & YI & $1 . \varepsilon$ & 0 & رعاية الأطفال وتتشئتهم \\
\hline $1 \ldots$ & ro. & ry.9 & $1 \times 9$ & 09.1 & $Y \cdot V$ & $\varepsilon$ & $1 \leq$ & القدوة \\
\hline $1 \ldots$ & ro. & $V Y$ & YצY & TY.r & $\vee \wedge$ & $1 . \mathrm{V}$ & 7 & تيسير التعليم \\
\hline $1 \ldots$ & ro. & $\Lambda$. & r^. & $10 . \mathrm{V}$ & 00 & $\varepsilon . r$ & 10 & تعليم مبادئ الدين \\
\hline $1 \ldots$ & ro. & $v \cdot .7$ & $r \leqslant V$ & 10.1 & or & $1 \varepsilon . r$ & 0. & الإعداد للحياة العملية \\
\hline
\end{tabular}

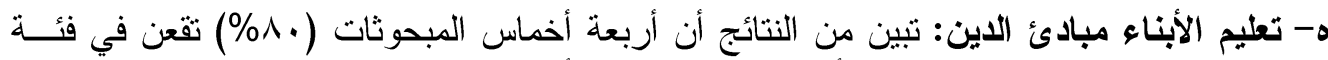

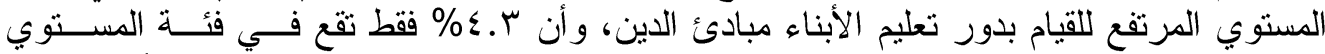
المنذفض للقيام بهذا الدور، و علي هذا يتضح إرتفاع قيام المبحوثات بدورهن في تعليم الأبناء مبادئ

دينهم.

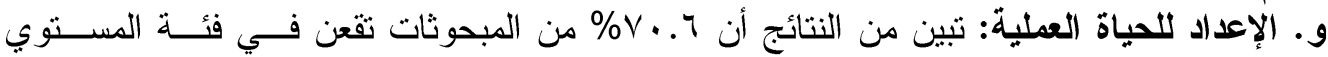

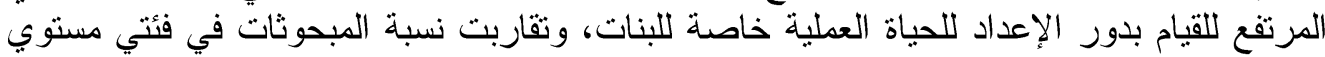

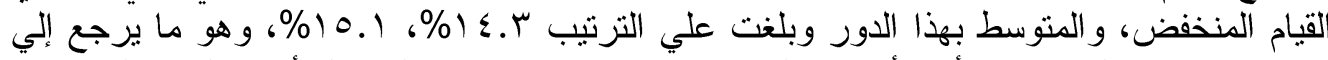

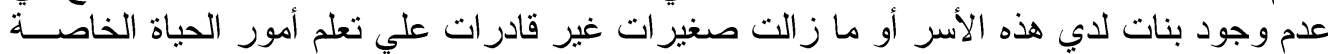

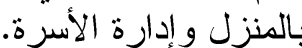
رابعاً: علاقة وجود المشكلات الأسرية بأداء الزوجات الأودات لأدوارهن

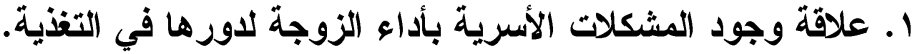

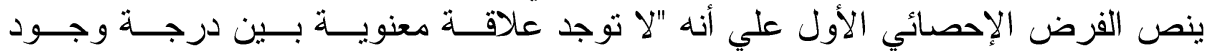

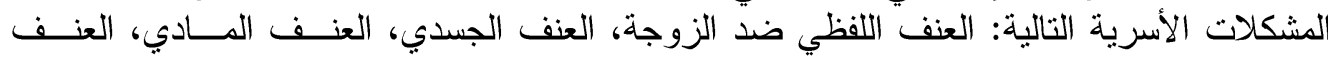

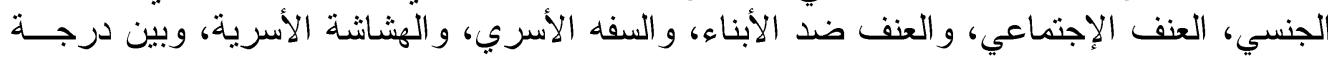
أداء الزوجة لأورها في تغذية الإنية الأسرة. و لإختبار صحة هذا الَفرض تم استخدام معامل الإرتباط البسيط لبيرسون وجاءت النتائج علي النحو

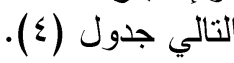

Fayoum J. Agric. Res. \& Dev., Vol. 32, No.1, January, 2018 


\section{IAr}

- تبين وجود علاقة إرتباطية عكسية عند مستوي معنوية ا +. . ب بين وجــود المشـــاتلات التاليــة:

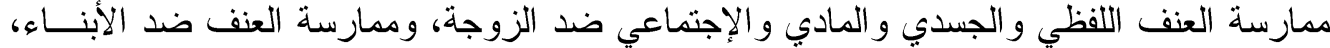

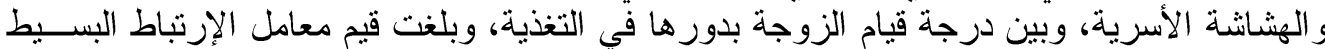

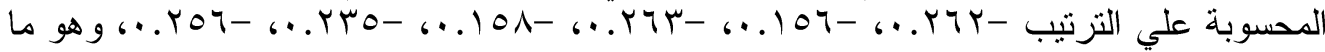

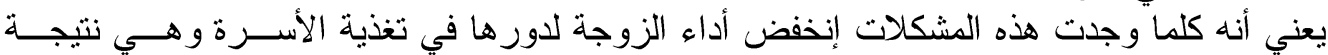

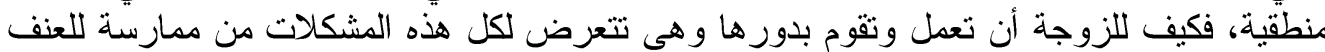

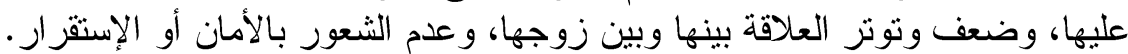

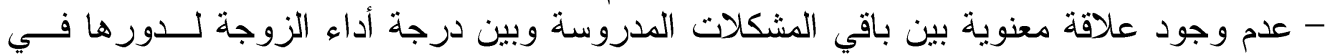

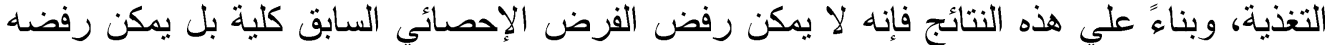

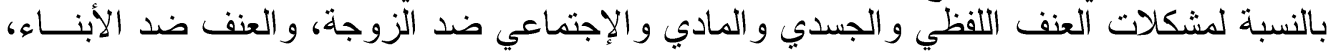

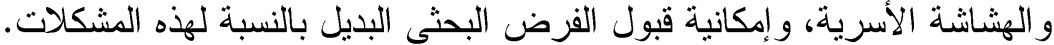
جدول (ع): قيم معامل الإرتباط البسيط المحسوبة بين المشكلات الأسرية وبين الإنين أداء الزئة الزوجة

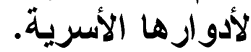

\begin{tabular}{|c|c|c|c|c|c|c|}
\hline الإعداد للحياة & تعليم مبادئ الاين & تيسير التعليم & القدوة & روائة الإطفال & التغذية & أدوار \\
\hline \multicolumn{7}{|c|}{ العنف ضد الزوجة } \\
\hline ***..।^9- & **..Y\V- &. $.1 r$ & **.. YOr & $* * . .191-$ & ***イイ .YY- & - اللفظى \\
\hline$* * . . I V \vee-$ & $* * . .1 \leq 9-$ &..$+Y T$ &..+49 & $* * \ldots 94-$ & $* * \ldots 107-$ & - الجسدي \\
\hline ***.YYOO- & $* * . . Y \leqslant 0-$ & $\ldots \times q 9-$ & $* * . . Y . \Sigma$ & **..KIM- & **..TYו- & - المادي \\
\hline$. . . \wedge 9-$ & $\ldots 7$ & $\ldots \wedge 1$ & ...M4 & $. .+r \Lambda-$ & $.999-$ & - الجنسي \\
\hline$* * . .10 \%-$ & $* . .117-$ & $* * . . I V r$ & ***. . I. & $. \vee \vee Y-$ & $* * . .10 \wedge-$ & - الإجتماعي \\
\hline **..Yrq- & $* * . .177-$ & $. . .7 V-$ &..$+1 r$ & ***.YMY- & ***.YMO- & العنف ضد الأبناء \\
\hline$\ldots, \mathrm{V}-$ & $* * . .101-$ & $* *$ *.Y\A- & $* . .1 \leq 9$ & $\ldots . \wedge 9-$ & $. r q-$ & السفه الأسري \\
\hline$* *$ *.Y.O- & **..YTQ- & $. .99 V-$ & $\ldots v$. & $* * . . \mid \vee \wedge-$ & **..Y०Y- & الهشاشة الأسرية \\
\hline
\end{tabular}

r. علاقة وجود المشكلات الأسرية بأداء الزوجة لاورها في رعاية الأطفال وتنشئتهم.

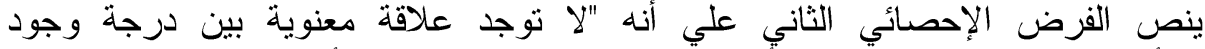

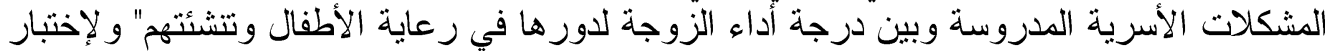

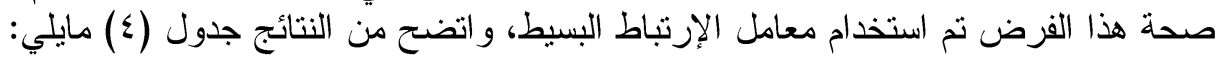

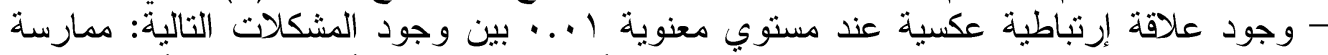

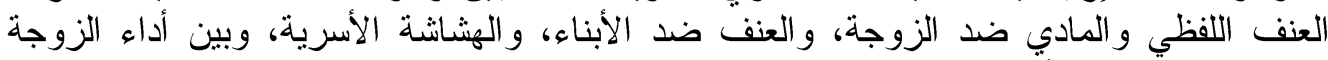

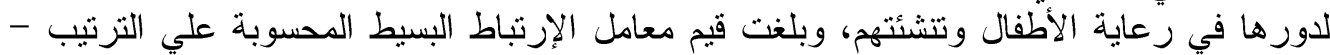
..IVA- 6..YTY- 6..YIT- 6..191

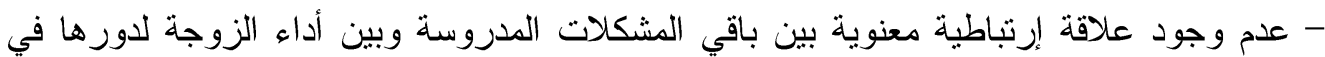

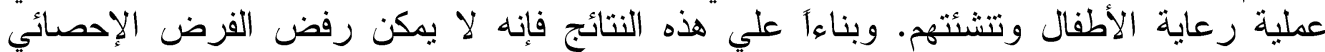

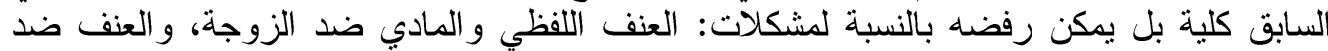

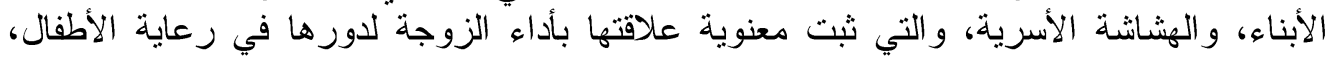

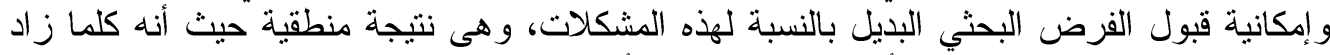

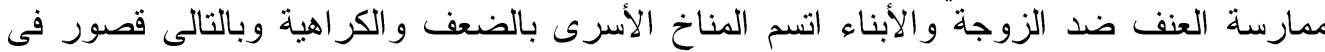

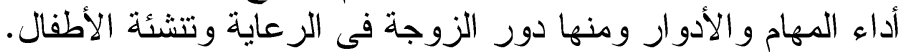

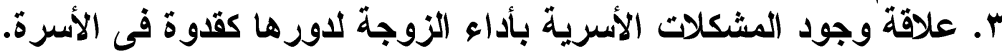

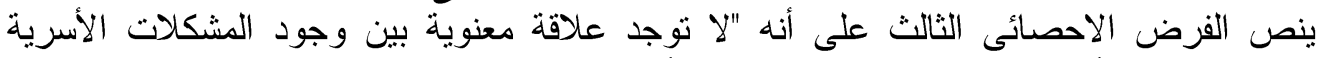
المدروسة، وبين أداء الزوجة لدورئه ها كقدوة في الأسرة"

Fayoum J. Agric. Res. \& Dev., Vol. 32, No.1, January, 2018 
$1 \wedge r$

و لاختبار صحة هذا الفرض تم استخدام معامل الارتباط البسيط لبيرسون، وجاءت النتائج على النحو

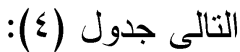

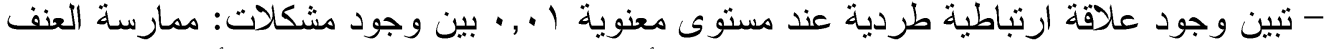

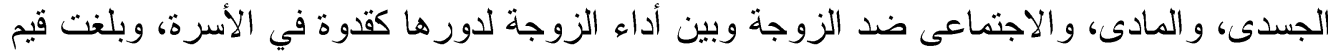

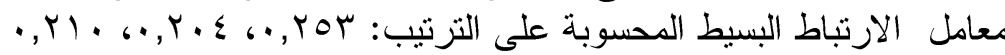

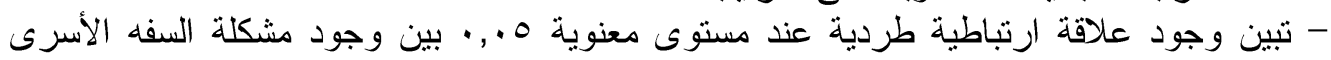

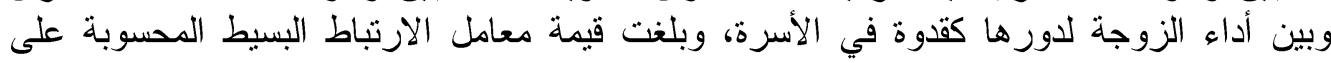
$\cdot, 1 \leqslant 9$

- عدم وجود علاقة معنوية بين باقى المشكلات الأسرية المدروسة وبين أداء الزوجة لدورها كقدوة

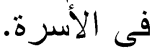

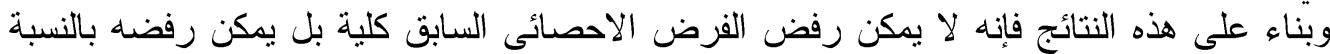

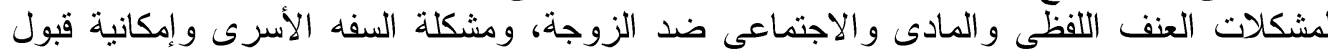

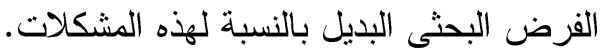

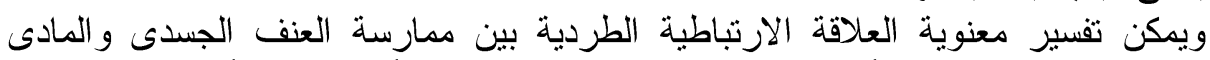

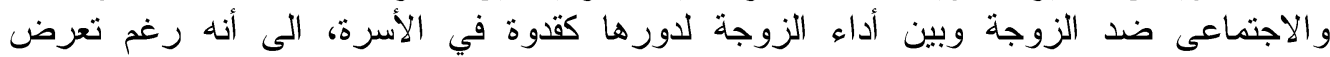

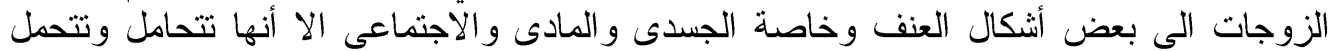

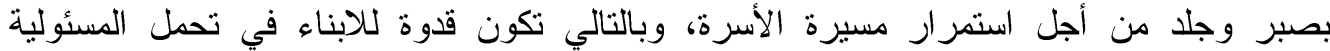

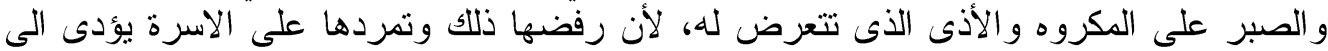

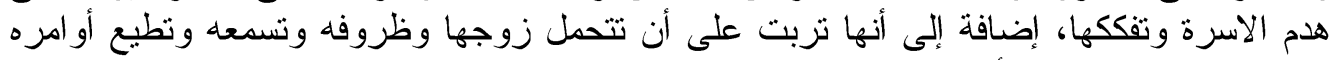

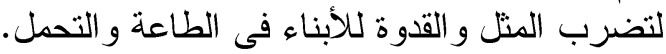

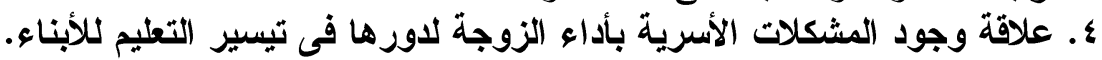

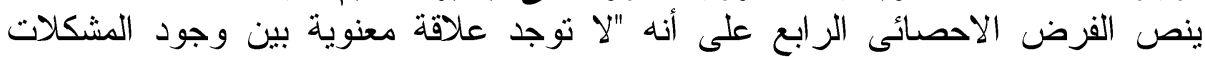

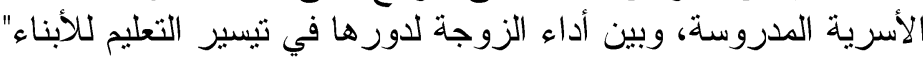

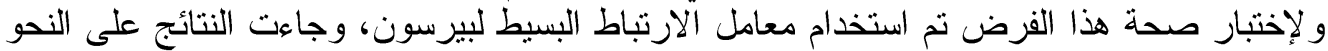

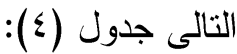
- تبين وجود علاقة ارتباطية طردية عند مستوى معنوية ال إل, • بين وجود مشكلات: ممارسة العنف

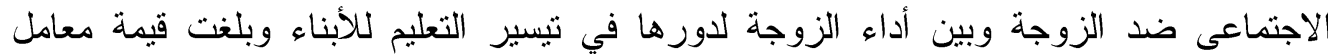

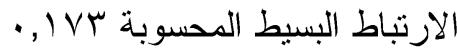

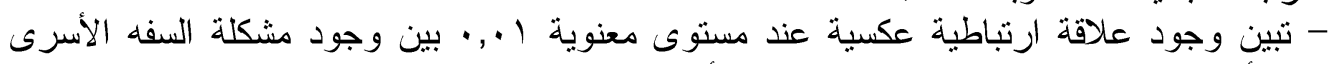
وبين أداء الزوجة لدورها في تيسير التعليم للأبناء ، وبلغت قيمة فئنة معامل الارتباط البسيط المحسوبة

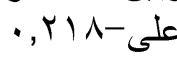
- عدم وجود علاقة معنوية بين باقى المشكلات الأسرية المدروسة وبين أداء الزوجة لدورها في تيسير التعليم للأبناء

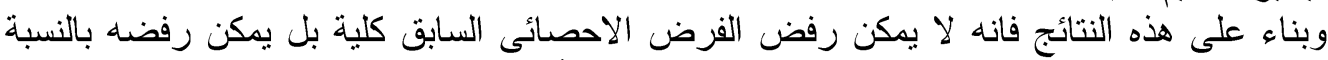

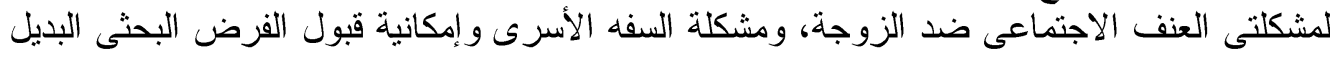

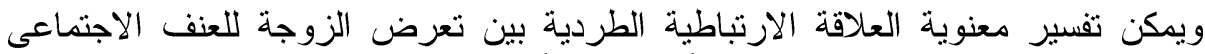

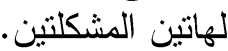

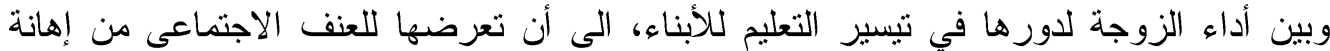

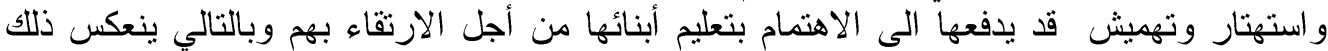

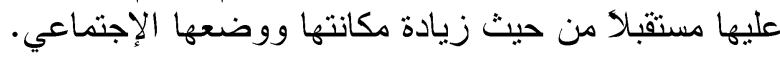

Fayoum J. Agric. Res. \& Dev., Vol. 32, No.1, January, 2018 
$1 \wedge \varepsilon$

اما معنوية العلاقة العكسية مع مشكلة السفه الأسرى حيث أن زيادة السفه الأسرى قد يفسد الأبناء

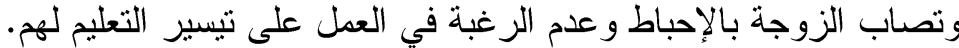

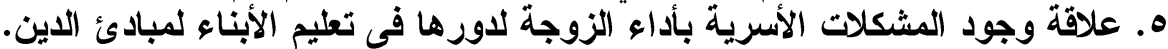

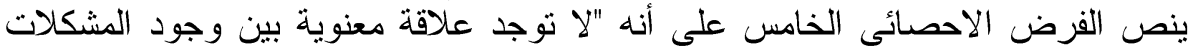

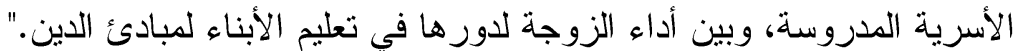

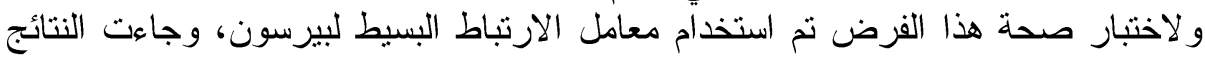

على النحو التالى جدول (飞):

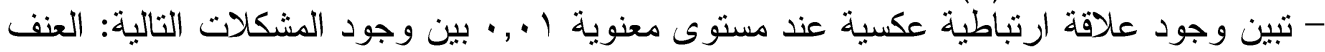

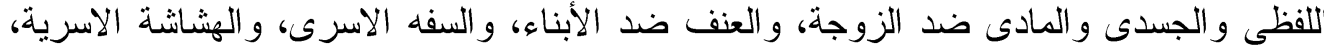

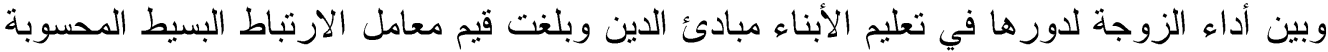
-

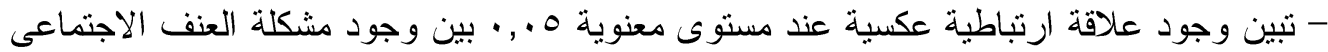

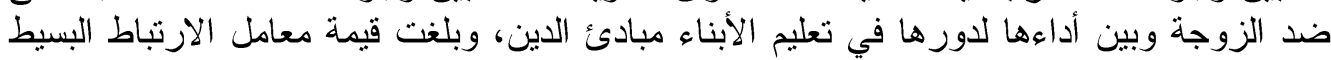

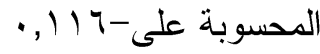
- عدم وجود علاقة معنوية بين باقى المشكلات الأسرية المدروسة وبين أداء الزوجة لدورها في تعليم الأبناء أمور دينهم. وبناء على هذه النتائج فانه لا لانئن يمكن رفض الفرض الأحصائى السابق كلية بل يمكن رفضه بالنسبة

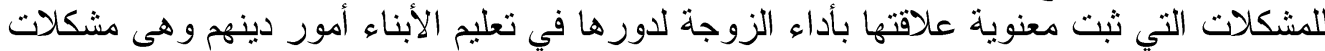

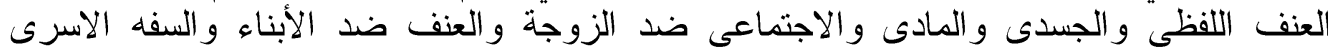

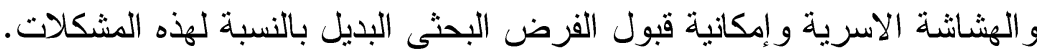

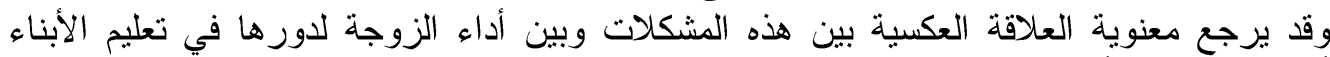

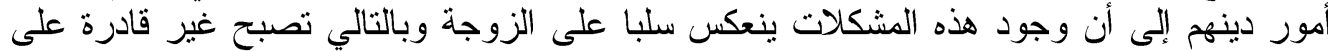

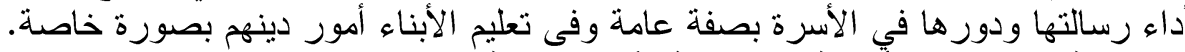

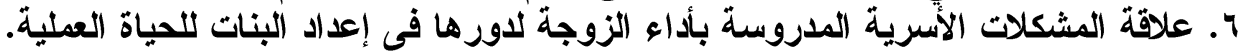

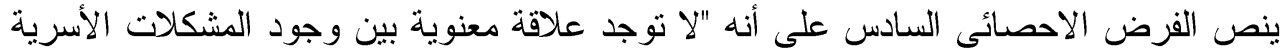

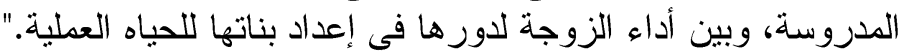

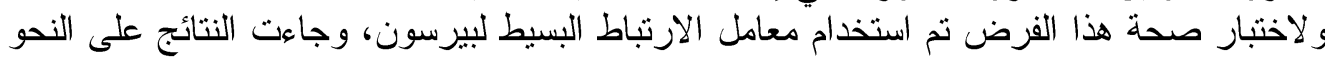

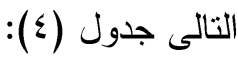
- تبين وجود علاقة ارتباطية عكسية عند مستوى معنوية ا.+,. بين وجود المشكلات الاسرية

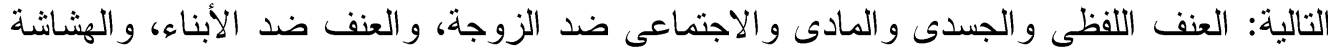

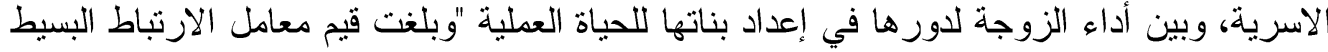

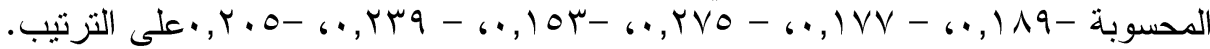

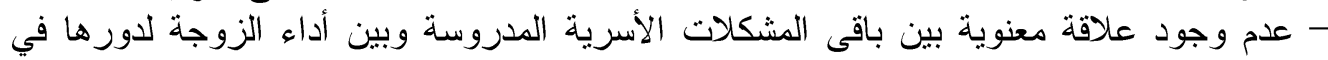
إعداد بناتها للحياه العملية. وبناءً على هذه النتائج فإنه لا يمكن رفض العض الفرض الاحصائى السابق كلية بل يمكن رفضه بالنسبة للمشكلات التي ثبت معنوية علاقتها بأداء الزوجة لدورها في إعداد البنات للحياة العملية، ومشكلات العنف اللفظى و الجسدى و المادى والاجتماعى ضد الزوجة و العنف ضد ضد الأبناء و الهشاشة

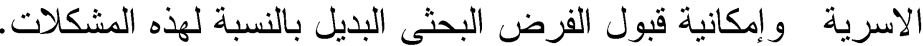

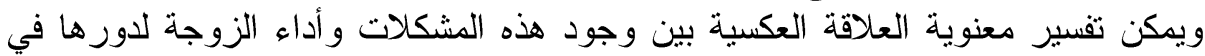

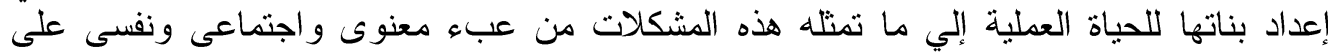

Fayoum J. Agric. Res. \& Dev., Vol. 32, No.1, January, 2018 
110

الزوجة، يجعلها غير قادرة على القيام بدور ها فى إعداد بناتها للحياة العملية، لأنه فى الغالب ما يكثر غياب الزوجة عن المنزل وذهابها إلى أهلها هربأ من جحيم الحياة الزوجية. توصيات البحث: تونة

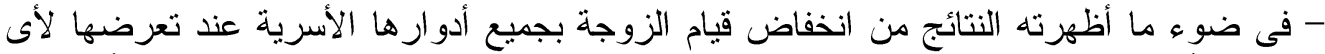

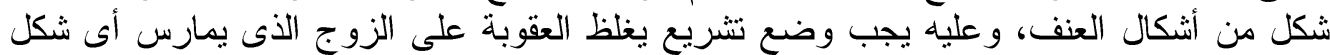

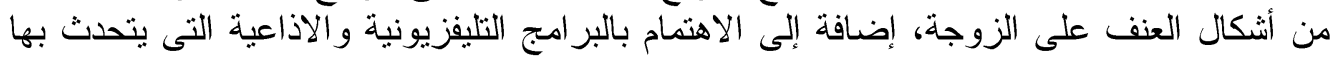

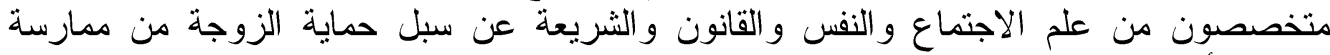

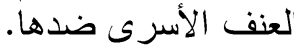

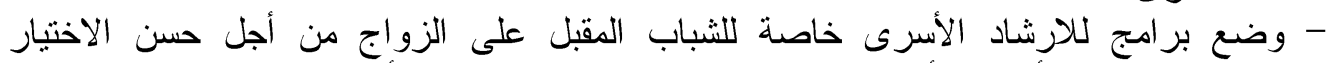

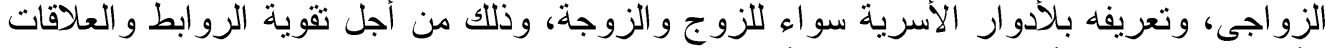

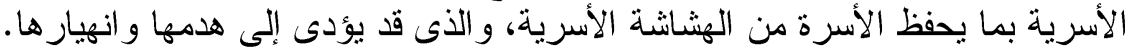

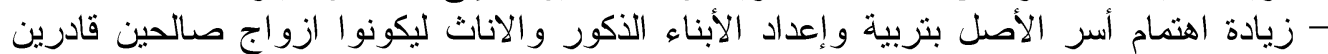

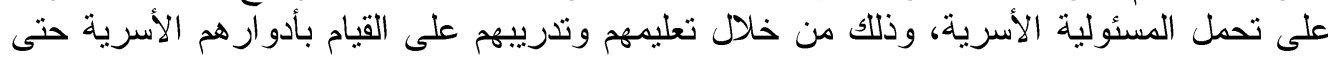

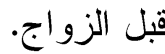

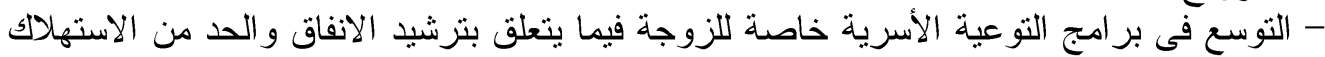

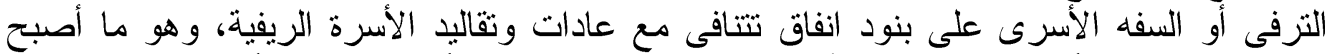
يمنل عبء على الأسرة يؤدى إلى نشأة مشكلات جديدة تؤثر على ألى أداء الادو ار الأسرية بها.

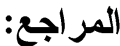

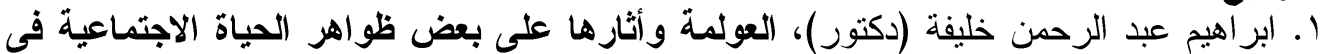

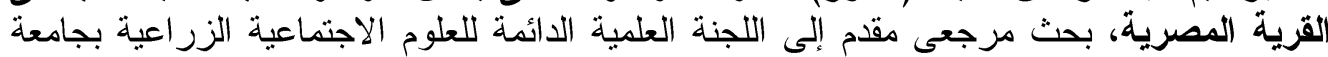

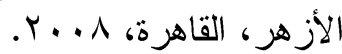

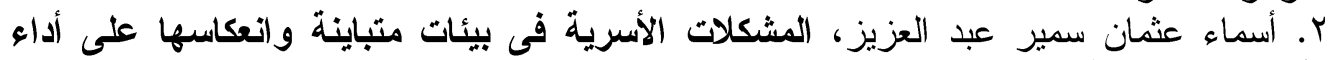

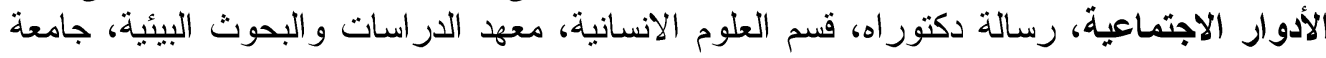

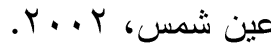
r. الخولى سالم الخولى (دكتور)، الأسرة المصرية: قراءة في ماضيها وحاضر ها ومستقبلها، كلية

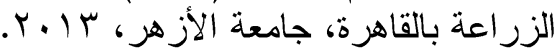

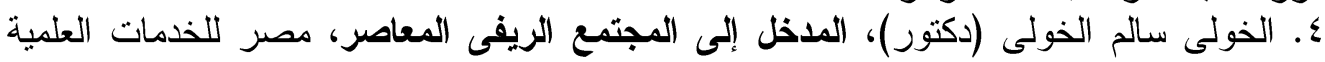

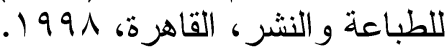
0. الخولى سالم الخولى (دكتور)، المشكلات الاجتماعية المعاصرة فى المجتمع المصرى، دار

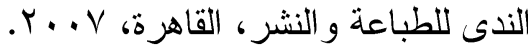

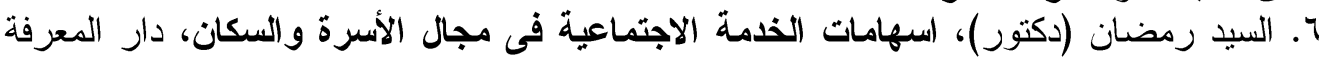

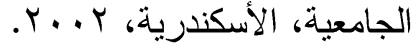

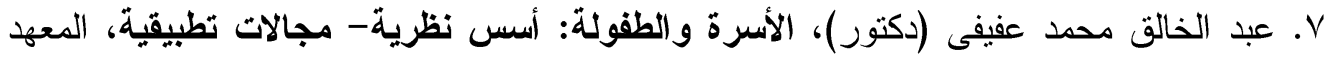

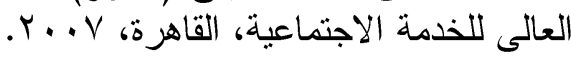

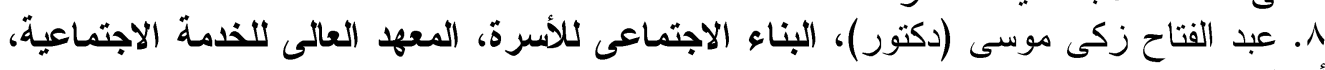

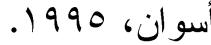
9. محمد أحمد بيومى (دكتور)، علم الاجتماع العائلى: دراسة التغيرات فى الأسرة العربية، دار

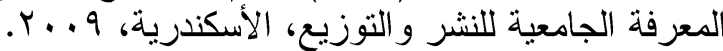

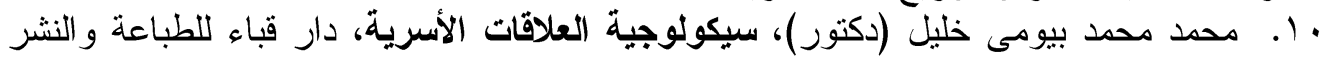

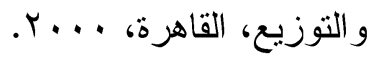

Fayoum J. Agric. Res. \& Dev., Vol. 32, No.1, January, 2018 
119

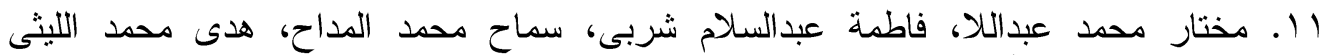

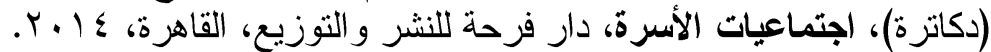

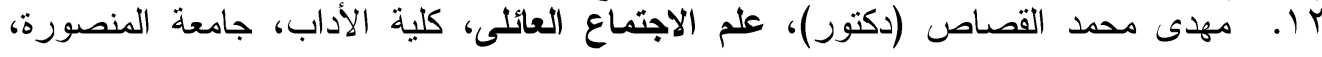

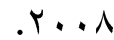

\title{
FAMILY PROBLEMS AND THEIR RELATION TO THE WIFES PERFORMANCE OF HER MARITAL ROLES STUDY IN SOME VILLAGES OF ALGHARBIA GOVERNORATE
}

\author{
Hoda Mohamed EL-lithey \\ Assistant prof. of Rural family development. Faculty of home economics. \\ Al_Azhar university
}

\begin{abstract}
The study aimed at identifying the extent of the following family problems: violence against the wife in its various forms (verbal, physical, financial, sexual, and social), also, the violence against children, family salaciousness, family fragility and the degree to which wives perform their marital roles, and the relation between the existence of these problems and the wives Studied roles.

The study was conducted in three villages selected randomly from three districts in Al Gharbia governorate. The sample was 350 wives. A prepared questionnaire was used to collect the data. The data were collected in a personal interview with the respondents in March and April 2017. After collecting the data, it was statistically analyzed using numerical scale tables, percentages and Pearson's simple correlation coefficient.

The most important results were as follows:

- The majority of respondents were in the low-level category of violence against the wife, the highest percentage was $94.3 \%$ for sexual violence, and the lowest $60.6 \%$ was verbal violence, while the lowest percentage was in the high level of violence against the wife. The highest was $8.9 \%$ of verbal violence, and the lowest $0.6 \%$ for sexual violence.

- The highest percentage of respondents $(58.3 \%)$ sees that the problem of family salaciousness exist in moderate degree, and the lowest percentage (4\%) see it as high.

- The majority of respondents $(79.7 \%)$ sees that the problem of family fragility is low, and the lowest percentage $2.6 \%$ sees its presence high.

- The majority of the respondents see that they are performing their marital roles with a high degree namely: nutrition, child care, child socialization, facilitating education, teaching children the principles of religion, preparing girls for practical life.
\end{abstract}

Fayoum J. Agric. Res. \& Dev., Vol. 32, No.1, January, 2018 
I AV

- There is an inverse relationship between the existence of the following family problems: violence against the wife, violence against the children, family fragility, and the wife's performance of her role in nutrition.

- There is an inverse relationship between the existences of the following family problems: violence against the wife, violence against children, family fragility, and the performance of the wife for her role in children care and socializing them.

- There is a direct relationship between the existence of the following family problems: violence against the wife, family salaciousness, and the performance of the wife role as an example.

- There is an inverse coloration between the existence of the following family problems: social violence against the wife, family salaciousness, and the performance of the wife's role in facilitating the education for the children.

- There is an inverse correlation between all the studied family problems except the problem of sexual violence against the wife, and between the performance of the wife for her role in teaching children the principles of religion.

- There is an inverse correlation between the existence of the following family problems: violence against the wife, against the children, and family fragility, and between the performance of the wife for her role in preparing the girls for practical life. 